Daiane Gil Franco

\title{
Efeito da Melatonina Sobre a Viabilidade de Células Granulares de Cerebelo em Cultura Depende do Contexto Celular
}

São Paulo

2014 


\section{Daiane Gil Franco}

\section{Efeito da Melatonina Sobre a Viabilidade de Células Granulares de Cerebelo em Cultura Depende do Contexto Celular}

Tese apresentada ao Instituto de Biociências da Universidade de São Paulo, para a obtenção de Título de Doutora em Ciências, na Área de Fisiologia Geral.

Orientador(a):

Regina Pekelmann Markus

São Paulo 


\section{Ficha catalográfica}

\section{Franco, Daiane Gil}

Efeito da melatonina sobre a viabilidade de células

granulares de cerebelo em cultura depende do contexto celular /

Daiane Gil Franco ;

Orientadora: Regina P. Markus. -- São Paulo, 2014.

$102 \mathrm{f}$.

Tese (Doutorado) - Instituto de Biociências da

Universidade de São Paulo. Departamento de Fisiologia.

1. melatonina. 2. cerebelo. 3 . NF-KB. I. Universidade de

São Paulo. Instituto de Biociências. Departamento de Fisiologia. II. Título. 


\section{Comissão Julgadora}

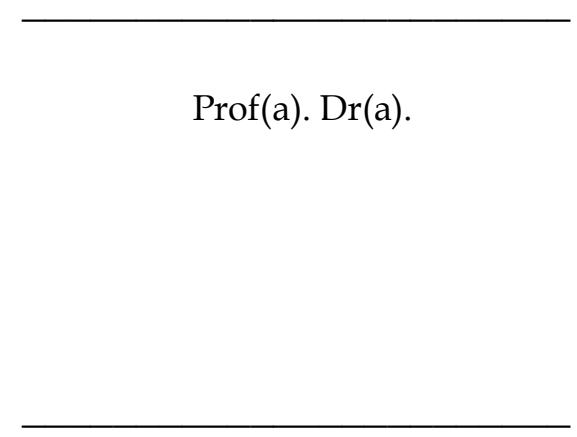

Prof(a). Dr(a).
Prof(a). Dr(a).

Prof(a). Dr(a).

Prof(a). Dr(a). Orientador(a) 


\section{AGRADECIMENTOS}

Esta tese é o final de uma jornada de dez anos de trabalho e de reatização. Esse tempo jamais tería sido tão proveitoso e tão especial se não fossem as pessoas envolvidas em todos os aspectos da minha vida. Por isso, quero expressar meus agradecimentos em poucas palavras, mas com sentimentos verdadeiros.

Agradeço à minha orientadora Regina pela eterna disposição, incentivo e também pelas críticas. Todo seu apoio foi fundamental para o mew crescimento profissional e pessoal.

Agradeço à todos os amigos que estão ou um dia estiveram no laboratório e contribuiram sempre para men aprendizado: Profa. Zulma, Marco Antônio, Camila, Adriessa, Cláudia, Eugênia, Luis, Flávia, Lívia, Leticia, Eliana, Michelle, Marina, Sanseray, Leita, Gabi Kinker, Gabi Santos, Gabi Souza, Luciana, Danito, Alex, Kelly, Natati, Cecília, Mara, Livingstone e Eduardo Tamura. Um agradecimento especial ao Prof. Pedro e à Erika por terem contribuido com sugestões e criticas muito importantes para a construção dessa tese. E também agradeço a tantos outros amigos que conheci no Departamento de Fisiologia. De todos vocês vou guardar com carinho os melhores momentos.

Agradeço ao apoio técnico da querida Débora e do Eduardo Braga. 
Agradeço ao meu marido, meu melhor amigo Jútio, por todo sew amor, por estar sempre ao men lado, por sua generosidade e por tudo que representa na minha vida.

Agradeço ao tio Nivaldo, tia Oritda e o Victor pelo carinho e petos almoços de final de semana.

Agradeço às minhas irmãs (Viviane e Stéfanie), meus cunhados e à minha pequena sobrinha Heloisa.

Com muito amor agradeço aos mens pais que sempre me apoiaram è à eles dedico esse trabalho.

E por fim, agradeço ao apoío financeiro da FAPESP, CAPES e CNPq. 


\section{ÍNDICE}

\section{INTRODUÇÃO}

Melatonina e os Sítios de Produção 11

Mecanismos de ação da melatonina e proteção celular 16

Fator de transcrição nuclear kappa B (NF-kB) 20

Relação NF-kB e Melatonina - Eixo Imune-Pineal 22

Cerebelo - as células granulares 26

OBJETIVOS 29

MATERIAL E MÉTODOS 31

Animais 32

Drogas e Reagentes 32

Protocolos Experimentais 35

Viabilidade Celular 36

Ensaio de Eletromobilidade em Gel (Eletromobility-shift assay - EMSA) 37

Expressão da enzima iNOS 38

Produção de óxido nítrico 39

Expressão da enzima AA-NAT 40

Dosagem de melatonina 41

Análise Estatística 41

RESULTADOS 43

Melatonina desempenha efeito dual sobre a viabilidade celular 44

Melatonina modula a via do fator de transcrição NF-KB 45

Expressão de iNOS 48

Aumento de óxido nítrico induz morte celular 51

Células granulares do cerebelo em cultura expressam AA-NAT e produzem melatonina 52 Melatonina endógena protege as células do cerebelo da morte celular induzida por LPS 55 
Efeitos citoprotetores da melatonina - integração do cerebelo ao eixo Imune-Pineal 58

Efeitos citotóxicos da melatonina 62

Considerações finais 67

CONCLUSÕES 70

RESUMO 72

ABSTRACT 74

REFERÊNCIAS 76

SÚMULA CURRICULAR 93

ANEXO I 101 


\section{Lista de Abreviaturas}

\begin{tabular}{|c|c|}
\hline 5-HT & 5-hidroxitriptamina (serotonina) \\
\hline 5-HTP & 5-hidroxitriptofano \\
\hline AA-NAT & arilalquilamina- $\mathrm{N}$-acetiltransferase \\
\hline $\mathrm{AC}$ & adenilil ciclase \\
\hline AFMK & N1-acetil-N2-formil-5-metoxiquinuramina \\
\hline AMK & $\mathrm{N}[1]$-acetil-5-metoxiquinuramina \\
\hline AMPc & adenosina monofosfato cíclica \\
\hline $\mathrm{ATP}$ & adenosina trifosfafo \\
\hline ANVISA & Agência Nacional de Vigilância Sanitária \\
\hline BDNF & fator neurotrófico derivado do cérebro \\
\hline BSA & albumina sérica bovina \\
\hline $\mathrm{Ca}^{2+}$ & Cálcio \\
\hline $\mathrm{CaM}$ & Calmodulina \\
\hline CaMKII & proteína quinase II dependente de CaM \\
\hline cNOS & sintase de óxido nítrico constitutiva \\
\hline c.p.m. & contagem por minuto \\
\hline CREB & proteína ligante ao elemento de resposta do AMPc \\
\hline DAF-FM & 4-amino-5-metilamino-2',7’'difluorofluoresceina \\
\hline DMEM & meio de Eagle modificado por Dulbecco \\
\hline DMSO & Dimetilsulfóxido \\
\hline DNA & ácido desoxirribonucleico \\
\hline DTT & Ditiotreitol \\
\hline e.p.m. & erro padrão da média \\
\hline EDTA & ácido etilenodiaminotetraacético \\
\hline EMSA & ensaio de eletromobilidade em gel \\
\hline GABA & ácido gama-aminobutírico \\
\hline GFAP & proteína fibrilar ácida de glia \\
\hline GMPc & guanosina monofosfato cíclico \\
\hline $\mathrm{G}_{\mathrm{s}}$ & proteína G estimulatória \\
\hline $\mathrm{H}$ & Hora \\
\hline HEPES & ácido 4-(2-hidroxietil)-1-piperazinaetanesulfonico \\
\hline HIOMT & hidroxi-indol-O-metiltransferase \\
\hline i.c.v. & intracerebroventricular \\
\hline IкB & proteína inibitória kappa B \\
\hline IKK & IkB quinase \\
\hline IL-2 & interleucina 2 \\
\hline IL-6 & interleucina 6 \\
\hline iNOS & sintase de óxido nítrico induzível \\
\hline $\mathrm{IP}_{3}$ & inositol trifosfato \\
\hline LPS & lipopolissacarídeo de bactéria Gram-negativa \\
\hline MAP2 & proteína associada ao microtúbulo 2 \\
\hline $\min$. & Minuto \\
\hline $\mathrm{mM}$ & Milimolar \\
\hline $\mathrm{MT}_{1}$ & receptor de melatonina do subtipo 1 \\
\hline $\mathrm{MT}_{2}$ & receptor de melatonina do subtipo 2 \\
\hline MTT & 3-(4,5-Dimetiltiazol-2-yl)-2,5-difeniltetrazolium \\
\hline
\end{tabular}




\begin{tabular}{|l|l|}
\hline NA & Noradrenalina \\
\hline NADPH & nicotinamida adenina dinucleotideo fosfato-oxidase \\
\hline NAS & N-acetilserotonina \\
\hline NEMO & proteína moduladora essencial de NF-KB \\
\hline NF-KB & fator nuclear kappa B \\
\hline NIK & proteína quinase indutora de NF-kB \\
\hline NLS & sinal de localização nuclear \\
\hline nNOS & sintase de óxido nítrico neuronal \\
\hline NO & óxido nítrico \\
\hline NP40 & nonil fenoxilpolietoxiletanol \\
\hline NPV & núcleo paraventricular \\
\hline NSQs & núcleos supraquiasmáticos \\
\hline OH• & radical hidroxila \\
\hline PAMPs & padrões moleculares associados a patogênos \\
\hline PBS & solução tampão fosfato \\
\hline PDTC & pirrolidina ditiocarbamato \\
\hline PKAII & proteína quinase dependente de AMPc \\
\hline PKC & proteína quinase dependente de Ca ${ }^{+}$ \\
\hline PMSF & fluoreto de fenilmetilsulfonil \\
\hline poli(dIdC) & Poli(deoxinosinico-deoxicitidílico) \\
\hline QR2 & quinona redutase 2 \\
\hline RHD & domínio de homologia Rel \\
\hline RNA & ácido ribonucleico \\
\hline RNS & espécie reativa de nitrogênio \\
\hline RORa & receptor órfão para retinóide do subtipo a \\
\hline ROS & espécie reativa de oxigênio \\
\hline RZR & receptor z para retinóide \\
\hline seg. & Segundo \\
\hline SFB & soro fetal bovino \\
\hline SNC & sistema nervoso central \\
\hline TAD & domínio de transativação \\
\hline TBE & solução contendo Tris/ Borato/EDTA \\
\hline TLR-4 & receptor semelhante ao Toll do subtipo 4 \\
\hline TNF & fator de necrose tumoral \\
\hline TNF-R & receptor de TNF \\
\hline TrkB & receptor de BDNF \\
\hline V & ultra violeta \\
\hline
\end{tabular}




\section{INTRODUÇÃO}

"Existe uma coisa que uma longa existência me ensinou: toda a nossa ciência, comparada à realidade, é primitiva e inocente; e, portanto, é o que temos de mais valioso."

Albert Einstein 
O fator de transcrição nuclear kappa B (NF-kB) exerce importantes funções na fisiologia e na patologia do sistema nervoso central (SNC). É um alvo de ação da melatonina, molécula sintetizada por diversos tipos celulares e que desempenha múltiplas ações. Encontramos na cultura de células granulares de cerebelo um bom modelo para estudar a interação entre a melatonina e a via de ativação do NF-kB, pois estas células dependem de uma atividade basal deste fator de transcrição para sobreviver.

\section{Melatonina e os Sítios de Produção}

A melatonina (N-acetil-5-metoxitriptamina) é uma indolamina versátil, muito conservada entre os filos e que está presente em organismos unicelulares, plantas, fungos, invertebrados e vertebrados (Pandi-Perumal et al., 2006). Em vertebrados é sintetizada pela glândula pineal à noite e por isso é conhecida como o hormônio do escuro, pois marca a entrada e a duração desta fase (Arendt e Skene, 2005). Além disso, outros sítios de produção de melatonina estão espalhados por todo o organismo e, neste caso, esta indolamina desempenha diversas funções autócrinas ou parácrinas, relacionadas ou não à marcação do tempo (Gern e Ralph, 1979; Bubenik, 2001; 2002; Carrilo-Vico et al., 2004; Markus et al., 2013).

A melatonina foi isolada pela primeira vez por Aaron B. Lerner a partir de extratos de glândula pineal bovina (Lerner et al., 1958). Mais tarde, Julius Axelrod fez importantes avanços descrevendo a síntese da melatonina (Axelrod 
e Wiessbach, 1960; Weissbach et al., 1960) e a participação do sistema nervoso simpático na imposição do ritmo diário de produção desse hormônio pela glândula pineal (Iversen, 2006). A síntese de melatonina tanto pela glândula pineal quanto por sítios extra-pineais depende da mesma via biossintética, no entanto, os controles envolvidos nessa síntese são diferentes para cada local. A biossíntese da melatonina se inicia com a captação do triptofano que é convertido a 5-hidroxitriptofano (5-HTP). Este é metabolizado em serotonina (5HT) que sofre uma acetilação pela enzima arilalquilamina-N-acetiltransferase (AA-NAT) resultando em $\mathrm{N}$-acetilserotonina (NAS) que é, em seguida, uma $O$ metilada pela enzima hidroxindol-O-metiltransferase (HIOMT), resultando em melatonina (Klein et al., 1981).

Nos mamíferos, a glândula pineal é um órgão neuroendócrino que recebe tanto informações neurais quanto humorais (Simonneuax e Ribelayga, 2003). A principal via neural que envolve a glândula pineal é chamada de trato retino-hipotalâmico que transmite a informação fótica da retina para os núcleos supraquiasmáticos (NSQs) localizados no hipotálamo (Moore e Klein, 1974). Os NSQs liberaram o neurotransmissor inibitório ácido gama-aminobutírico (GABA) no núcleo paraventricular (NPV) que emite projeções ao gânglio cervical superior, de onde partem fibras simpáticas que inervam a pineal. Na fase de claro, a informação fótica que chega aos NSQs leva a uma inibição da atividade do NPV e, portanto, inibe a via de ativação da glândula pineal. Na fase de escuro, esta via é liberada e os neurotransmissores simpáticos ativam a pineal (Simonneuax e Ribelayga, 2003). Apesar da luz ser sincronizadora da 
atividade da pineal, não podemos esquecer que os NSQs apresentam uma atividade rítmica endógena. Isso quer dizer que, em escuro constante, a glândula pineal produz melatonina de forma rítmica, obedecendo ao ritmo endógeno dos NSQs (Arendt e Skene, 2005).

A noradrenalina liberada no escuro de terminais simpáticos originários do gânglio cervical superior (Klein, 1985) ativa adrenoceptores a $\alpha_{1}$ e $\beta_{1}$ (Tobin et al., 2002). A ativação apenas do adrenoceptor $\beta_{1}$ é suficiente para induzir a síntese de melatonina. Estes receptores acoplam-se à proteína G estimulatória $\left(\mathrm{G}_{\mathrm{s}}\right)$ resultando na produção de adenosina monofosfato cíclica (AMPc) através da adenilil ciclase $(\mathrm{AC})$. $\mathrm{O} A M P c$, por sua vez, ativa a proteína quinase A II dependente de AMPc (PKAII) (Simonneax e Ribelaga, 2003). O aumento da atividade simpática pode elevar as concentrações disponíveis de NA na fenda sináptica ativando adrenoceptores $\alpha_{1}$ (Sabban et al., 2004; Serova et al., 2008) que potencia em até vinte vezes a síntese de melatonina induzida pela ativação de adrenoceptores $\beta_{1}$ (Chik e Ho, 1989). Os adrenoceptores $\alpha_{1}$ ativam fosfoquinase C (PKC) através da mobilização de cálcio por inositol trifosfato $\left(\mathrm{IP}_{3}\right)$. A PKC induz um aumento de guanosina monofosfato cíclica (GMPc) que ativa a $A C$ (Simonneuax e Ribelayga, 2003).

Entre os mamíferos podemos distinguir dois grupos quanto à ativação da produção de melatonina pela pineal: os de hábito noturno (roedores) e os de hábito diurno (primatas e ungulados). Em roedores PKAII fosforila o fator de transcrição CREB (do inglês, cyclic AMP response element binding) que ativa a transcrição do RNA mensageiro da enzima AA-NAT. Uma vez transcrita e 
traduzida, esta enzima é degradada pelo proteassoma 26S. A fosforilação da AA-NAT por PKAII favorece a interação com a proteína 14-3-3, tornando-a estável e expondo o sítio ativo. Portanto, em roedores a ativação $\beta_{1}$-adrenérgica sinaliza a transcrição do gene da AA-NAT, sua estabilização e ativação. Em primatas e ungulados, o gene $A a-n a t$ é transcrito e traduzido constitutivamente, porém a proteína AA-NAT sofre processo contínuo de degradação na ausência de fosforilação. A indução de sua atividade depende, portanto, da fosforilação pela PKAII, obtida através da ativação simpática. Em ambos os grupos, a enzima AA-NAT é o passo chave da síntese de melatonina (Simonneaux e Ribelayga, 2003), mas o decurso temporal de ativação é diferente. No caso dos animais de hábito noturno existe um tempo longo entre a entrada do escuro e o início da produção de melatonina, enquanto que em animais de hábito diurno a subida dos níveis de melatonina ocorre imediatamente após o início do escuro (Lee et al., 2009).

Como mencionado anteriormente, a via de biossíntese de melatonina em sítios extra-pineal é a mesma já descrita, mas o controle dessa produção é específico para cada local. Em estado de higidez, células fotorreceptoras da retina, por exemplo, são as responsáveis pela produção de melatonina de forma rítmica sincronizada ao ciclo claro/escuro ambiental (Gern e Ralph, 1979; Cahill e Besharse, 1993; Liu et al., 2004), mas em condições patológicas outros tipos celulares também assumem este papel (Tosini et al., 2012a). Em ambos os casos, a melatonina age apenas no local (Iuvone et al., 2005). O controle da expressão da enzima AA-NAT em fotorreceptores depende apenas do relógio circadiano 
interno presente nessas células e não da atividade dos NSQs (Chen e Baler, 2000; Sakamoto et al., 2000).

Células do trato gastrointestinal, com destaque para as células enterocromafins, produzem elevado nível de melatonina que chega a ser 10 à 100 vezes maior que as concentrações encontradas no plasma (Bubenik, 2002). Ao contrário da produção fotoperiódica na pineal, a libertação de melatonina gastrointestinal parece estar relacionada com a periodicidade da ingestão de alimentos e esta produção tem ação endócrina, parácrina ou autócrina, influenciando a regeneração e a função epitelial e modulando o sistema imunológico local (Bubenik, 2008).

A produção de melatonina por células do sistema imunológico ocorre quando essas células são ativadas por agentes pró-inflamatórios, tais como padrões moleculares associados a patógeno (PAMPs) ou citocinas (CarriloVicco et al., 2004; 2005; Martins et al., 2004; Pontes et al., 2006; Maldonado et al., 2010; Muxel et al., 2012; Pires-Lapa et al., 2013). A melatonina produzida por células imunocompetentes tem função autócrina e parácrina, uma vez que aumenta a capacidade fagocítica dos macrófagos (Muxel et al., 2012; Pires-Lapa et al., 2013) e induz a síntese de interleucina-2 (IL-2) (Carrilo-Vico et al., 2005).

No SNC os altos níveis de melatonina encontrados no líquido cefalorraquidiano podem ter origem na própria glândula pineal que se comunica com o terceiro ventrículo através do recesso pineal (Tricoire et al., 2002). Por outro lado, o tecido cerebral apresenta a maquinaria molecular necessária para produzir melatonina (Gaudet et al., 1991; Uz et al., 2002; 
Jimenez-Jorge et al., 2006) e existem evidências de que esta produção seja feita por células da glia, já que expressam AA-NAT (Liu et al., 2007; Tan et al., 2010; Pinato et al., 2013). A importância dos altos níveis de melatonina encontrados no SNC pode estar relacionada à função neuroprotetora da melatonina (Hardeland, 2012).

A melatonina, portanto, exerce diversas funções que podem ser divididas em cronobióticas e não-cronobióticas. Os efeitos cronobióticos são mediados pelo ritmo diário de produção de melatonina pela glândula pineal, enquanto que a melatonina produzida por sítios extra-pineal não depende de sincronização pelo ciclo claro-escuro e tem ação no local de síntese.

\section{Mecanismos de ação da melatonina e proteção celular}

É largamente difundido o papel da melatonina como agente de proteção celular, tanto em modelos in vivo quanto in vitro. Podemos citar uma extensa literatura mostrando a melatonina inibindo apoptose em diversos tipos celulares (Yalcin et al., 2004; Luchetti et al., 2010), protegendo as células do estresse oxidativo (Solís Herruzo e Solís Muños, 2009; Esposito e Cuzzocrea, 2010; Cuesta et al., 2011) ou, ainda, combatendo os efeitos do envelhecimento (Srinivasan et al., 2005; Perreau et al., 2007; Pizza et al., 2011). As múltiplas funções desempenhadas pela melatonina, específicas para cada tecido, se devem aos diversos mecanismos de ação possíveis. Muitas das funções da melatonina são mediadas por dois tipos de receptores de membrana acoplados 
à proteína G (Zlotos et al., 2013). Por outro lado, por ser uma molécula anfipática a melatonina é capaz de atravessar a membrana plasmática e interagir com moléculas citosólicas e nucleares com uma afinidade muito menor do que para os receptores de membrana. (Shida et al., 1994; Hardeland, 2009; Luchetti et al., 2010).

Em mamíferos os receptores de membrana denominados $\mathrm{MT}_{1}$ e $\mathrm{MT}_{2}$ (originalmente descritos como $\mathrm{Mel}_{1 \mathrm{a}}$ e $\mathrm{Mel}_{1 \mathrm{~b}}$, respectivamente) são expressos tanto individualmente como em conjunto em vários tecidos e órgãos (Hardeland, 2009). O subtipo $\mathrm{MT}_{1}$ é amplamente expresso no SNC, em órgãos reprodutores, rim, fígado, vasos e pele. Nos NSQs, por exemplo, desempenha um papel na retroalimentação envolvida no reajuste do oscilador, já que a glândula pineal de mamíferos é controlada pelos NSQs. Já o subtipo $\mathrm{MT}_{2}$ é expresso de forma mais restrita, sendo encontrada principalmente no cérebro (com excessão dos NSQs), embora a sua presença também tenha sido detectada no pulmão, células do sistema imunológico, duodeno e adipócitos (PandiPerumal et al., 2008). Esses receptores tem afinidades diferentes para a melatonina sendo cerca de três vezes maior para o $\mathrm{MT}_{1}$ em relação ao $\mathrm{MT}_{2}$. (Witt-Enderby et al., 2003). Além disso, os receptores podem atuar como monômeros ou dímeros, sendo que a presença de heterodímero $\mathrm{MT}_{1} / \mathrm{MT}_{2}$ e o homodímero $\mathrm{MT}_{1}$ são mais prevalentes em relação ao homodímero $\mathrm{MT}_{2}$ (Zlotos et al., 2014).

Um terceiro tipo de receptor de membrana $\left(\mathrm{MT}_{3}\right)$ chegou a ser designado, mas, posteriormente, foi demonstrado que se tratava de uma 
enzima citosólica denominada quinona redutase 2 (QR2) (Nosjean et al., 2000). Esta enzima pertence ao grupo de redutases que participa da proteção contra o estresse oxidativo (Pandi-Perumal et al., 2008). Além da QR2 a melatonina interage com outras moléculas citosólicas como, por exemplo, a calmodulina (CaM) que forma um complexo com cálcio (Hardeland, 2009; Luchetti et al., 2010). Essa interação leva a inibição da atividade de proteínas quinases, como a CaM quinase II (CaMKII) (Benítez-King et al., 1996) e da isoforma constitutiva da sintase de óxido nítrico (cNOS) (León et al., 2000).

A superfamília de receptores órfãos de ácido retinóico (ROR e RZR) tem sido alvo de um considerável número de estudos que apontam que esses receptores estão presentes no SNC e em células do sistema imunológico (Hardeland, 2009). A atividade desses receptores pode ser inibida pela melatonina de forma direta ou através de duas formas indiretas: via receptor $\mathrm{MT}_{1}$ ou através da interação da melatonina com o complexo CaM (TomásZapico e Coto-Montes, 2005).

Um alvo chave da melatonina envolvido na proteção celular é o fator de transcrição NF-kB (Luchetti et al., 2010). Sua inibição leva, consequentemente, a redução da síntese de citocinas proinflamatórias como, por exemplo, as interleucinas (IL-2 e IL-6), o fator de necrose tumoral (TNF), moléculas de adesão e quimiotáxicas e a isoforma induzida da sintase de óxido nítrico (iNOS), além de modular a expressão de genes anti e proapoptóticos (Bhakar et al., 2002; Bruck et al., 2004; Kaltschmidt et al., 2005). O mecanismo de ação da 
melatonina sobre a via de ativação deste fator de transcrição ainda não está estabelecido.

Múltiplas ações da melatonina a tornam uma importante molécula no combate ao estresse oxidativo. Devido às suas características físico-químicas a melatonina se encontra amplamente distribuída nos tecidos, células e compartimentos celulares (Shida et al., 1994; Costa et al., 1995; Menendez-Pelaez e Reiter, 1993). Isso permite que ela interaja e neutralize espécies reativas de oxigênio (ROS) ou de nitrogênio (RNS), reduzindo os danos oxidativos às moléculas encontradas em compartimentos lipídicos ou aquosos (Tomás-Zapico e Coto-Montes, 2005). A propriedade única da melatonina ao interagir com ROS ou RNS gera metabólitos que também possuem propriedades antioxidantes, tal como o $\mathrm{N}^{1}$-acetil-N22-formil-5-metoxiquinuramina (AFMK) que sofre a retirada do grupo funcional formil dando origem ao também antioxidante N[1]-acetil-5metoxiquinuramina (AMK) (Galano et al., 2013).

A melatonina também age como antioxidante de forma indireta por estimular o aumento da expressão e da atividade de enzimas antioxidantes, tal como a superóxido dismutase, glutationa peroxidase, glutationa redutase e glicose-6-fosfato desidrogenase (Pandi-Perumal et al., 2013). Os mecanismos ainda são incertos, mas existem evidências da ação antioxidante da melatonina através de seus receptores de membrana (Carrilo-Vico et al., 2004) ou através da inibição dos fatores de transcrição RORa e NF-kB, ambos envolvidos na transcrição de genes de enzimas pró e antioxidantes (Dai et al., 2001; Luchetti et al., 2010). 
Por fim, a melatonina apresenta múltiplas formas de gerar citoproteção associadas às diversas formas específicas de sinalizar.

\section{Fator de transcrição nuclear kappa B (NF-kB)}

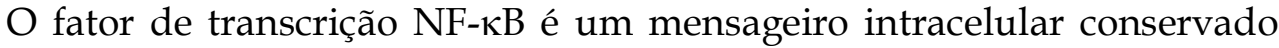
evolutivamente que exerce um papel crucial em muitos processos biológicos (Hayden e Gosh, 2012). Descoberto em linfócito B (Sen e Baltimore, 1986) o NFкB é considerado um fator chave na reposta do sistema imunológico, mas também influencia a expressão gênica relacionada à sobrevivência, diferenciação e proliferação celular (Xiao, 2004). A disfunção da atividade do NF-kB pode levar a consequências severas tais como câncer, doenças cardiovalaculares, diabetes, inflamações crônicas e doenças relacionadas ao SNC (Courtois e Gilmore, 2006).

A superfamília de proteínas do NF-kB é caracterizada por conter uma porção N-terminal bem conservada com cerca de 300 aminoácidos chamada de domínio de homologia Rel (RHD), a qual se subdivide em uma região que se liga ao DNA e outra chamada de domínio de dimerização, onde se encontra um sinal de localização nuclear (NLS) (Hayden e Ghosh, 2004). A sequência cterminal divide a superfamília do NF-kB em dois grupos: os que contém um domínio de transativação (TAD) e que, portanto, ativam a transcrição gênica RelA (p65), RelB e c-Rel - e os que não contém esse domínio e são repressores da expressão gênica - p50 e p52 (Gilmore e Woleski, 2012). Os membros dessa 
superfamília funcionam como dímeros e as cinco subunidades podem formar homo ou heterodímeros, sendo que o mais abundante é o p50/RelA (Xiao, 2004).

A atividade dos dímeros de NF-kB é inibida por proteínas citoplasmáticas inibitórias da família IkB que se ligam ao domínio RHD dos dímeros, mantendo-os no citoplasma, prevenindo a translocação para o núcleo. A família IkB é caracterizada por repetições de anquirinas que são proteínas adaptadora que promovem interação proteína-proteína (Xiao, 2004). Fazem

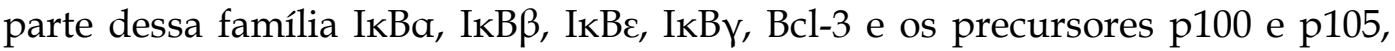
que dão origem as subunidades p52 e p50, respectivamente (Gilmore e Wolenski, 2012).

As vias de ativação do NF-kB podem ser dependente (via clássica) ou independente (via não-clássica) do complexo formado pelas proteínas ІкB quinases (IKK) dos subtipos a e $\beta$ e da proteína moduladora essencial de NF-KB (NEMO). Na via clássica, a ativação de receptores de agentes pró-inflamatórios, tal como TNF ou de PAMPs, como o lipopolissacarídeo (LPS), componente da parede de bactéria gram-negativa que ativa o receptor semelhante ao Toll do subtipo 4 (Toll-like receptor, TLR-4), levando a ativação do complexo IKK $\beta$ que está associado ao complexo IKKa/NEMO. A ativação deste complexo leva à fosforilação da proteína IkB que será, então, ubiquitinada e degradada por proteassoma liberando o dímero de NF-kB (Hayden e Ghosh, 2012). A via nãoclássica é independente de IKK $\beta$ e NEMO, enquanto que IKKa e a proteína quinase indutora de NF-kB (NIK) são essenciais. Algumas citocinas e vírus 
ativam a NIK que ativa IKKa. Esta fosforila p100 que é poliubiquitinada e parcialmente degradada, gerando a subunidade p52 que transloca para o núcleo juntamente com a RelB (Xiao, 2004). Além dessas vias, danos no DNA causados por radiação ionizante ou por drogas quimioterápicas e condições estressantes, como estresse oxidativo, são capazes de ativar NEMO através de uma via "núcleo-citoplasma". Ainda, a luz UV é capaz de ativar IкBa via p38 de forma independente de dano no DNA (Neumann e Naumann, 2007).

Ao translocar para o núcleo o NF-kB ativa a transcrição dos genes da proteína da família IKB gerando uma retroalimentação negativa que controla a atividade do próprio fator de transcrição (Nelson et al., 2004). Na presença de um estímulo sustentado o NF-kB transloca para dentro e para fora do núcleo, produzindo uma oscilação com período definido. Em células de neuroblastoma humano (SK-N-A) isoladas este período é de aproximadamente cem minutos (Ashall et al., 2009; Turner et al., 2010). Esta oscilação temporal permite que diferentes conjuntos de genes sejam expressos ao longo do tempo (Ashall et al., 2009). Além dessa retroalimentação outros fatores regulados pelo NF-kB são capazes de modular a atividade desse fator de transcrição como, por exemplo, o NO sintetizado a partir da iNOS (delaTorre et al., 1999).

\section{Relação NF-kB e Melatonina - Eixo Imune-Pineal}

A produção rítmica de melatonina pela glândula pineal pode ser modulada por mediadores inflamatórios já que a glândula expressa receptores 
para eles (Jiang-Shieh et al., 2005; da Silveira Cruz-Machado et al., 2010; Carvalho-Sousa et al., 2011). Enquanto isso, na periferia células imunocompetentes produzem melatonina quando estimuladas por esses mesmos agentes inflamatórios (Carrilo-Vicco et al., 2004; 2005; Martins et al., 2004; Pontes et al., 2006, 2007; Maldonado et al., 2010; Muxel et al., 2012; PiresLapa et al., 2013). Essa comunicação bidirecional entre as fontes de melatonina pineal e extra-pineal no contexto de uma inflamação (Skwarlo-Sonta et al., 2003; Markus et al., 2007; Markus e Ferreira, 2011) é dependente da atividade do NFкB (da Silveira Cruz-Machado et al., 2010, 2012; Carvalho-Souza et al., 2011). Esta relação tem sido estudada por nosso grupo como a hipótese do Eixo Imune-Pineal (Markus et al., 2007; Fernandes e Markus, 2011; Markus e Ferreira, 2011; Markus et al., 2013).

Em estado de higidez a melatonina produzida pela glândula pineal na fase de escuro inibe o rolamento e a adesão de leucócitos à camada endotelial dos vasos, impedindo a migração dessas células para o tecido e, portanto, a montagem de uma resposta inflamatória desnecessária (Lotufo et al., 2001; 2006). A glândula pineal apresenta um ritmo de atividade diário do dímero inibidor de transcrição gênica, p50/p50. Na transição claro/escuro, momento em que se inicia a produção de melatonina pela glândula, há uma queda abrupta do conteúdo nuclear desse dímero, que permanece baixo até a próxima fase de claro (Cecon et al., 2010).

No início de um processo inflamatório a ativação de receptores de PAMPs e de citocinas (TLR-4 e TNF-R) na glândula pineal leva a um aumento 
da translocação nuclear dos dímeros p50/p50 e p50/RelA induzindo a produção de TNF e de iNOS e um bloqueio da produção de melatonina (da Silveira Cruz-Machado et al., 2010, 2012; Carvalho-Souza et al., 2011; Markus e Ferreira, 2011). A ausência de TAD no dímero p50/p50 e o fato de que culturas de pineais incubadas com inibidores de NF- $\kappa B$ aumentam a produção de NAS (Ferreira et al., 2005) sugerem que este dímero seja responsável pelo bloqueio da expressão da Aa-nat.

A síntese de melatonina por células imunocompetentes ativadas por agentes pró-inflamatórios foi demonstrado em linfócitos (Carrilo-Vico et al., 2004; 2005), macrófagos (Martins et al., 2004; Muxel et al., 2012; Pires-Lapa et al., 2013), células mono e polimorfonucleares de colostro (Pontes et al., 2006, 2007), timócitos (Naranjo et al., 2007), mastócitos (Maldonado et al., 2010) e células da glia (Pinato et al., 2013). A produção de melatonina por macrófagos do colostro

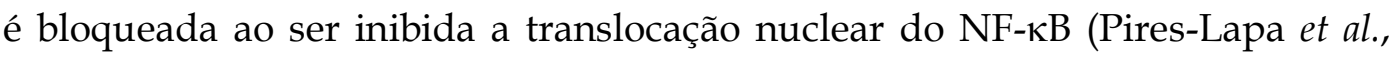
2013) e, em linhagens de macrófagos RAW 264.7, a expressão do gene da AANAT é acionada por dímeros de NF-kB contendo as subunidades RelA ou c-Rel (Muxel et al., 2012). Esta melatonina produzida por macrófagos age de maneira parácrina ativando receptores $\mathrm{MT}_{2}$ que leva a um aumento da expressão de dectina-1, molécula que participa no englobamento de partículas e microorganismos e na formação do fagolisossomo. Portanto, a melatonina induz um aumento da atividade fagocítica dos macrófagos (Pire-Lapa et al., 2013). 
Se por um lado a síntese de melatonina tanto na pineal quanto em sítios extra-pineal é modulada pelo NF-kB, a atividade deste fator de transcrição é inibida pela melatonina em macrófagos de murino (Gilad et al., 1998), neuroblastoma humano (Lezoualc'h et al., 1998), linhagem de célula humana (SH-SY5Y) (Chetsawang et al., 2006), cultura de endotélio de rato (Tamura et al., 2009) e em microglia de murinos (Min et al., 2012), reduzindo tanto a síntese de citocinas pró-inflamatórias quanto o estresse oxidativo induzido por agentes nocivos. Por essa razão, o uso da melatonina tem sido considerado no tratamento e prevenção de diversas doenças de caráter inflamatório, incluindo doenças neurodegenerativas (Hardeland, 2009).

Desta forma, a hipótese do Eixo Imune-Pineal postula que mediadores da fase inicial da inflamação bloqueiam a síntese de melatonina induzida por noradrenalina, inibindo o pico noturno de melatonina plasmática e favorecendo a migração de células para o local da lesão. Dados clínicos reforçam essa hipótese, mostrando que mães com mastite ou que realizaram parto cesariano apresentam uma supressão dos níveis noturnos de melatonina acompanhada de um aumento dos níveis de TNF plasmático (Pontes et al., 2006; 2007). Na fase de recuperação os leucócitos migram para o local da lesão celular e produzem melatonina e outros mediadores anti-inflamatórios que contribuem para o término da resposta inflamatória (Fernandes e Markus, 2011). 


\section{Cerebelo - as células granulares}

O cerebelo (latim: pequeno cérebro) é uma região do encéfalo responsável pelo controle motor fino e por funções cognitivas e emocionais (Hashimoto e Hibi, 2012). O córtex do cerebelo é dividido anatomicamente em três camadas: molecular, Purkinje e granular. A camada molecular possui poucos corpos celulares de dois tipos de interneurônios (em cesto e estrelado) que estão dispersos entre os axônios excitatórios das células granulares e os dendritos inibitórios das células de Purkinje. Na camada de células de Purkinje, além destas, estão os núcleos das células de Bergmann, astrócitos especializados que lançam seus prolongamentos à camada molecular, perpendicularmente à superfície meníngea. A camada mais interna é composta pelo grande número de células granulares, os menores neurônios do corpo, e uma pequena quantidade de neurônios de Golgi. Nessa camada existem sinapses complexas denominadas glomérulos cerebelares, onde a fibra musgosa termina em um pequeno bulbo que se conecta com as células granulares e os neurônios de Golgi (Ghez e Thach, 2000).

As células granulares de cerebelo, que são neurônios glutamatérgicos, sobrevivem em cultura desde que o meio de cultivo seja mantido em concentração despolarizante de potássio $(25 \mathrm{mM})$ o que ativa os canais de cálcio dependente de voltagem elevando os níveis de cálcio intracelular (Blaustein, 1975; Tsien, 1983; Gallo et al., 1987). A redução dos níveis de potássio na cultura induz apoptose (D'Mello et al., 1993; Galli et al., 1995), enquanto que a abertura 
de canais de cálcio é indispensável para manter uma atividade basal do fator de transcrição NF-kB, essencial para a sobrevivência das células (Lilienbaum e Israël, 2003).

De forma geral, o NF-kB exerce diversas funções essenciais no SNC, tanto em condições fisiológicas quanto patológicas (Mattson et al., 2000; Kaltschmidt et al., 2005). A sobrevivência de células granulares de cerebelo em cultura mantidas em alta concentração de potássio é reduzida quando se incuba as células com bloqueadores da atividade do NF-kB. Por outro lado, células transfectadas que superexpressam a subunidade RelA não entram em apoptose quando submetidas a um meio com baixa concentração de potássio (Koulich et al., 2001). Esses resultados indicam que o NF-kB é indispensável para a sobrevivência dessas células em cultura e uma alteração dos níveis basais pode ocasionar a morte celular (Kaltschmidt et al., 2005).

O cerebelo é alvo de atuação da melatonina via receptores de membrana (MT1 e $\mathrm{MT}_{2}$ ) (Laudon et al., 1998; Al-Ghoul et al., 1998; Imbesi et al., 2008; Adamah-Biassi et al., 2014). Na cultura de células granulares do cerebelo a melatonina apresenta um efeito protetor contra a neurotoxicidade induzida por glutamato (Gepiredman et al., 2000) e o envelhecimento celular (Tajes Orduña et al., 2009). Além disso, a melatonina inibe corrente induzida pela ativação de receptores nicotínicos (Lax et al., 2008) e aumenta a amplitude da corrente de potássio, elevando a migração celular (Liu et al., 2007).

O cerebelo é capaz de sintetizar melatonina por um mecanismo dependente de NF-кB (Pinato et al., 2013). A injeção de LPS no ventrículo lateral 
de rato reduz o pico noturno de melatonina no plasma e induz a sua síntese no cerebelo, mas não no córtex e no hipocampo. Além disso, a mesma injeção de LPS induz morte celular apenas no córtex e no hipocampo, mas não no cerebelo, indicando que a produção de melatonina nesse tecido tem um papel citoprotetor.

A partir do embasamento teórico descrito, tendo em vista que a sobrevivência das células granulares de cerebelo em cultura depende de uma atividade basal do NF-kB e que estas células são alvos da melatonina, indagamos como esta indolamina afeta a atividade do NF-kB em condição basal ou em culturas desafiadas por agente que ativa a via do NF-kB. 


\section{OBJETIVOS}

"A vida se expande ou se encolhe de acordo com a nossa coragem"

Anais Nin 
Utilizar um modelo de células neuronais em cultura para avaliar se o efeito da melatonina é dependente do estado fisiopatológico do sistema. Culturas de células granulares de cerebelo foram avaliadas no estado basal e após desafio com LPS.

Objetivos específicos:

1) Avaliar se o efeito citoprotetor da melatonina depende do estado de ativação do fator de transcrição NF-kB nas células granulares de cerebelo.

2) Determinar se as células granulares de cerebelo em cultura expressam AA-NAT e produzem melatonina em condição basal ou quando estimuladas por LPS.

3) 


\section{MATERIAL e MÉTODOS}

"Os métodos são as verdadeiras riquezas"

Friedrich Nietzsche 


\section{Animais}

Ratos Wistar (7 - 8 dias de idade) foram obtidos do biotério do Departamento de Fisiologia do Instituto de Biociências, Universidade de São Paulo. Os animais permaneceram alojados em gaiolas de polipropileno mantidas em sala com temperatura e umidade controladas. O ciclo claro-escuro empregado foi de 12:12 horas. Todos os procedimentos seguiram as recomendações e os princípios éticos de experimentação animal, aprovados pelo comitê de ética do instituto (CEUA/IB 110/2010) e foram realizados em conformidade com as recomendações do Conselho Nacional de Controle de Experimentação Animal (CONCEA) (ANEXO 1). Foram utilizados cerca de 250 animais para a realização desse trabalho.

\section{Drogas e Reagentes}

As drogas e reagentes utilizados tiveram as seguintes procedências:

- Sigma-Aldrich (St. Louis, MI, EUA): tripsina; inibidor de tripsina; lipopolisacarídeo (LPS), de Escherichia coli sw sorotipo 0127:B8, melatonina, anticorpo anti-coelho conjugado a FITC (F7512), anticorpo de coelho anti-AA-NAT (S0939), ácido 4-(2-hidroxietil)1-piperazinaetanesulfonico (HEPES), bis-acrilamida $\left(\mathrm{N}, \mathrm{N}^{\prime}-\right.$ 
metilenebisacrilamida), brometo de 3-(4,5-Dimetiltiazol-2-il)-2,5difeniltetrazolio (MTT) e N-acetil-2-benzitriptamina (luzindol).

- Santa Cruz Biotechnology (Santa Cruz, CA, EUA): anticorpo policlonal de coelho anti-iNOS (NOS2 (N-20): sc-651 TRITC) e anticorpos para NF-kB p50 (NLS)X sc-114X, p52 (K-27)X sc-298X, RelA (A)X sc-109X, RelB (C-19)X sc-226X e c-Rel (N)X sc-70X.

- GIBCO BRL Products (Grand Island, NY, EUA): Dubeco's modified Eagles medium (DMEM); soro fetal bovino (SFB) e penicilina/estreptomicina.

- Amresco (Solon, Ohio, EUA): Triton X-100.

- Invitrogen Life Technology (Carlsbad, CA, EUA): ditiotreitol (DTT), fenilmetanesulfonilfluorido (PMSF) e quinase T4 polinucleotídeo.

- Amersham Bioscience (Buckinghamshire, UK) foram obtidos: sal ácido sódico Poli(deoxinosinico-deoxicitidílico) [poli(dIdC)].

- Bio-Rad (Richmond, CA, EUA): acrilamida.

- Calbiochem (Darmstadt, Germany): Nonidet-p40 (NP40).

- Perkin Elmer (Boston, MA, EUA): Easy Tides ${ }^{\circledR:}$ adenosina 5'trifosfato, $\left[\gamma^{32} \mathrm{P}\right]$.

- Promega (Madison, WI, EUA): Oligonucletotídeo consenso para NF-кB (5'-AGTTGAGGGGACTTTCCCAGGC-3').

- Molecular Probes (Eugene, OR, EUA): diacetato de 4-amino-5metilamino-2' $7^{\prime}$ 'difluorofluoresceina (DAF-FM DA), $1400 \mathrm{~W}$. 
- IBL international (Hamburg, Alemanha): kit de dosagem de melatonina.

Todos os demais reagentes utilizados apresentavam grau de pureza analítico. A melatonina foi diluída inicialmente em $5 \%$ de etanol, sendo estocada na concentração de $10 \mathrm{mM}$. Luzindol foi diluído e estocado na concentração de $10 \mathrm{mM}$ em $100 \%$ de etanol. DAF-FM foi estocado na concentração de $1 \mathrm{mM}$ em dimetilsufóxido (DMSO) 100\%. Todo o material restante foi diluído, aliquotado e estocado em água deionizada e purificada por sistema Milli-Q. As diluições seguintes foram feitas com as soluções descritas em cada protocolo.

\section{Cultura de Células Granulares de Cerebelo}

Os ratos foram decapitados e os cerebelos isolados foram lavados, picotados e incubados em tripsina 0,05 \% em solução fisiológica ( $\mathrm{NaCl} 120 \mathrm{mM}$; $\mathrm{KCl} 5 \mathrm{mM} ; \mathrm{KH}_{2} \mathrm{PO}_{4} 1,2 \mathrm{mM} ; \mathrm{MgSO}_{4} .7 \mathrm{H}_{2} \mathrm{O}$ 1,2 mM; $\mathrm{NaHCO}_{3} 25$ mM e glicose 13 $\mathrm{mM} ; \mathrm{pH}=7,4)$ a $37^{\circ} \mathrm{C}$ durante 40 minutos. Na sequência, a dispersão química foi interrompida pela adição de inibidor de tripsina $0,06 \%$ e as células isoladas por dispersão mecânica seguida de centrifugação (300 g, 5 min.) foram plaqueadas em meio DMEM: 13,4 g/L, SFB 10 \%, KCl 25 mM, NaHCO 44 mM, penicilina $50 \mathrm{U} / \mathrm{mL} /$ estreptomicina $50 \mu \mathrm{g} / \mathrm{mL}$, na concentração de $5 \times 10^{5}$ $5 \times 10^{6}$ células/poço, mantidas a $37^{\circ} \mathrm{C}, 5 \% \mathrm{CO}_{2}$. O meio de cultura foi trocado a 
cada 48 horas e os experimentos foram realizados no $7^{\circ}$ ou $8^{\circ}$ dia de cultura in vitro.

A imunofluorescência utilizando os anticorpos MAP-2 (marcador de neurônio), GFAP (marcador de astrócito) e ED-1 (marcador de microglia) indicaram que a cultura é composta de 80 - 90 \% de neurônios (células granulares), 10 - $15 \%$ de astrócitos e 2 - $3 \%$ de microglias, semelhantemente à cultura descrita por Kawamoto e colaboradores (2008).

\section{Protocolos Experimentais}

Para avaliar a viabilidade celular as culturas foram incubadas com melatonina $(0,1 \mathrm{nM}-1 \mu \mathrm{M})$, LPS $(100 \mathrm{ng} / \mathrm{mL})$ ou ambos por 24 horas. Com o intuito de avaliar o papel da expressão da iNOS na viabilidade as células foram incubadas com o bloqueador seletivo 1400W $(1 \mu \mathrm{M})$ por 30 minutos antes dos tratamentos com LPS (100 ng/mL) ou melatonina (100 nM), seguindo por mais 24 horas de incubação. E para avaliar o papel da melatonina endógena na viabilidade as células foram incubadas com o antagonista não-seletivo de receptores de melatonina, luzindol $(100 \mathrm{nM})$ durante 24 horas na presença ou ausência de LPS (100 ng/mL).

Para avaliar a atividade do fator de transcrição NF-kB foi feita uma curva de concentração (10 nM - $1 \mu \mathrm{M}$; 15 min.) e uma curva de tempo (100 nM, 15 - 60 min.) para a melatonina. Além disso, foi avaliado o efeito da melatonina (100 
$\mathrm{nM}$ ) na atividade do NF-kB induzido por LPS (100 ng/mL) incubados por 15 minutos.

A expressão da iNOS foi induzida por LPS (100 ng/mL), melatonina (30 - $300 \mathrm{nM}$ ) ou ambos incubados por 30 - 120 minutos. A produção de NO foi avaliada após 24 horas de incubação com melatonina (100 nM), LPS (100 $\mathrm{ng} / \mathrm{mL}$ ) ou ambos.

A expressão da AA-NAT foi avaliada por imunocitoquímica em culturas de células incubadas com LPS (100 ng/mL) por 2, 4 e 6 horas. A dosagem de melatonina foi feita no meio de cultura de células incubadas com LPS (30 $\mathrm{ng} / \mathrm{mL}-1 \mu \mathrm{g} / \mathrm{mL}$ ) por 6 ou 12 horas.

Os veículos de melatonina continham $0,005 \%$ de etanol e o de luzindol $0,01 \%$ de etanol.

\section{Viabilidade Celular}

Culturas de células de cerebelo foram incubadas por 2 horas com MTT (5 $\left.\mu \mathrm{g} / \mathrm{mL}, 3{ }^{\circ} \mathrm{C}\right)$, um sal tetrazólio de coloração amarela. O MTT solúvel é reduzido por enzimas oxirredutases dependentes de NADPH transformando-se em um composto formazan insolúvel de coloração violeta. A atividade desta enzima indica, de forma indireta, as células que estão viáveis. Os cristais de formazan foram diluídos com DMSO (30 min. com agitação orbital) e a absorbância da solução violeta foi quantificada em um espectrofotômetro de placa (SpectraMax 250, Molecular Devices, Sunnyvale, CA) no comprimento de 
onda de $540 \mathrm{~nm}$. A viabilidade celular foi expressa em porcentagem da absorbância medida em células controles.

Ensaio de Eletromobilidade em Gel (Eletromobility-shift assay - EMSA)

Proteínas nucleares foram previamente extraídas das culturas de cerebelo como descrito por Ferreira e colaboradores (2005). De forma breve, as culturas foram homogeneizadas em tampão de lise (HEPES 10 mM, KCl 10 mM, EDTA 0,1 mM, DTT $1 \mathrm{mM}$, PMSF 0,1 mM), centrifugadas (12000 g, $1 \mathrm{~min}$.$) duas$ vezes e ressuspendidas em tampão de extração (HEPES 10 mM, KCl 500 mM, EDTA 1mM, DTT $1 \mathrm{mM}$, PMSF 0,1 mM). Após incubação de 15 minutos em gelo e centrifugação (2000 g, 5 min.) o sobrenadante contendo a proteína nuclear foi coletado e armazenado a $-20{ }^{\circ} \mathrm{C}$. A proteína nuclear total foi quantificada no espectrofotômetro ND-1000 (Nanodrop, Wilmington, DE, EUA) no comprimento de onda de $280 \mathrm{~nm}$. Seis microgramas da proteína foram incubadas em um volume final de tampão de ligação (Tris- $\mathrm{HCl} 10$ mM pH 7,5; $\mathrm{MgCl}_{2} 1 \mathrm{mM}$; NaCl 50 mM; DTT 0,5 mM; EDTA 0,5 mM; glicerol 4 \%; poli-dIdC $1 \mu \mathrm{g})$ por 20 minutos à temperatura ambiente.

Na sequência, cerca de 40000 c.p.m. de sonda de oligonucleotídeo dupla fita contendo a seqüência consenso de NF-кB (5’ AGTTGAGGGGACTTTCCCAGGC) marcada com үATP_32P foi adicionada por 30 minutos à temperatura ambiente. O complexo DNA-proteína foi 
analisado em gel não-desnaturante de poliacrilamida $6 \%$ em tampão Trisborato/EDTA (TBE 0,25x) a $150 \mathrm{~V}$ por 2,5 horas. O gel foi seco a vácuo, em seguida, exposto ao filme XAR-5 (Kodak ${ }^{\circledR}$, Rochester, NY, EUA) por 36 - 48 horas à $-70{ }^{\circ} \mathrm{C}$, revelado (solução reveladora e fixadora $\operatorname{Kodak}^{\circledR}$ ) e, por último, quantificado densitometricamente no programa ImageJ (Image Processing and Analysis in Java).

Para identificar as subunidades do NF- $\kappa$ B presentes em extratos proteicos nucleares incubamos os extratos protéicos nucleares com $2 \mu \mathrm{g} / \mu \mathrm{L}$ de anticorpos policlonal de coelho para p50, p52, RelA, RelB e c-Rel por 30 minutos temperatura ambiente. Estes foram incubados juntos aos extratos protéicos (30 min., temperatura ambiente) antes da adição do oligonucleotídeo. As subunidades presentes no extrato se conjugam ao anticorpo formando um complexo que fica retido no início do gel (super-shift). O EMSA foi realizado conforme descrito previamente.

\section{Expressão da enzima iNOS}

A expressão da enzima iNOS foi determinada de acordo com o protocolo adaptado de Ferrari e colaboradores (2008). Após os tratamentos descritos na sessão de Protocolos Experimentais, as células foram lavadas duas vezes em solução fosfato salina (PBS: $\mathrm{NaCl} 125 \mathrm{mM}, \mathrm{Na}_{2} \mathrm{HPO}_{4} 2 \mathrm{mM}, \mathrm{NaH}_{2} \mathrm{PO}_{4} 2 \mathrm{mM}$, $\mathrm{KCl} 5 \mathrm{mM})$ e fixadas em metanol/acetona (1:1, $\left.15 \mathrm{~min} .,-20^{\circ} \mathrm{C}\right)$. Em seguida, as

células foram lavadas três vezes com PBS e incubadas durante 30 minutos a 
temperatura ambiente com 0,2 \% de Triton X-100 diluído em PBS. Por fim, as células foram incubadas com anticorpo anti-iNOS (1:50) conjugado ao fluoróforo TRITC e, após 16 - 20 horas à $4{ }^{\circ} \mathrm{C}$, as células foram lavadas três vezes em PBS e as lâminas foram montadas com PBS:glicerol (1:1).

A fluorescência foi analisada em microscopia confocal (LSM 500, Carl Zeiss, New York, NY, EUA) em objetiva de imersão em óleo com aumento de 40 vezes, utilizando o laser $\mathrm{HeNe}(543 \mathrm{~nm})$ para excitação. Para quantificar a fluorescência, foi utilizado o software LSM510 (Carl Zeiss, LSM510) e apenas as células granulares, que foram identificadas e diferenciadas dos outros tipos

celulares presentes na cultura por sua morfologia, foram computadas. Cinco imagens contendo entre 15 - 25 células foram escolhidas aleatoriamente e fotografadas (1024 x 1024 pixels). Todos os parâmetros, incluindo abertura do pinhole, velocidade de escaneamento e potência do laser permaneceram os mesmos durante todo o experimento. A expressão da iNOS foi apresentada como porcentagem da média do grupo controle de cada experimento.

\section{Produção de óxido nítrico}

O nível de NO foi determinado conforme protocolo descrito previamente por Tamura e colaboradores, 2006. Após os devidos tratamentos (ver sessão Protocolos Experimentais), as células foram incubadas por 50 minutos em solução fisiológica contendo: $\mathrm{NaCl} 120 \mathrm{mM}, \mathrm{KCl} 25 \mathrm{mM}, \mathrm{NaH}_{2} \mathrm{PO}_{4}$ 1,2 mM, $\mathrm{MgCl}_{2}$ 1,3 mM, $\mathrm{CaCl}_{2} 2 \mathrm{mM}, \mathrm{NaHCO}_{3} 25 \mathrm{mM}$, glicose $11 \mathrm{mM}$ e L-arginina 10 
$\mathrm{mM}(\mathrm{pH}=7,4)$, à temperatura ambiente na presença do indicador fluorescente DAF-FM DA $(5 \mu \mathrm{M})$. O composto fluorescente foi excitado com laser argônio (488 nm) e a fluorescência emitida foi medida a 515 - 530 nm no microscópio confocal utilizando a objetiva de imersão em óleo com aumento de 40 vezes. A quantificação da fluorescência foi realizada seguindo o mesmo protocolo descrito para a expressão da iNOS, considerando apenas as células granulares. O nível de NO foi expresso como porcentagem em relação ao grupo controle de cada experimento.

\section{Expressão da enzima AA-NAT}

A expressão da enzima chave na síntese de melatonina, AA-NAT (anticorpo de coelho anti-AA-NAT c-terminal, Sigma 0689) foi avaliada em células granulares de cerebelo. As células granulares foram identificadas e diferenciadas dos outros tipos celulares por sua morfologia. Após os devidos tratamentos as células foram fixadas com paraformaldeído $\left(4 \%,-20{ }^{\circ} \mathrm{C}\right)$, lavadas com PBS, incubadas com solução de bloqueio (PBS, soro albumina bovina, BSA $1 \%$ e glicina $0,3 \mathrm{M}, 60 \mathrm{~min}$.). Em seguida, as culturas foram incubadas com anticorpo anti-AA-NAT (1:100) por cerca de 18 horas. Por fim, as células foram lavadas com PBS e incubadas por 1 hora à temperatura ambiente com anticorpo secundário anti-coelho conjugado ao fluorescente FITC (1:200), antes que as lâminas fossem finalmente montadas com PBS e glicerol $(1: 1)$ 
A fluorescência foi analisada em microscopia confocal (LSM 500, Carl Zeiss, New York, NY, EUA) equipado com objetiva de imersão em óleo com aumento de 40 vezes e o laser argônio (488 nm) para excitação. Para quantificar a fluorescência, foi utilizado o software LSM510 (Carl Zeiss, LSM510). Cinco imagens contendo entre 25 - 40 células granulares foram escolhidas aleatoriamente e fotografadas (1024 x 1024 pixels). Todos os parâmetro, incluindo abertura do pinhole, velocidade de escaneamento e potência do laser permaneceram o mesmo durante todo o experimento. A expressão da AA-NAT foi apresentada como porcentagem da média do grupo controle de cada experimento.

\section{Dosagem de melatonina}

A dosagem da melatonina foi feita através de kit comercial de ELISA (IBL, Hamburg, Alemanha).

\section{Análise Estatística}

Os resultados foram expressos como média \pm e.p.m. As diferenças entre os grupos experimentais foram testadas por análise de variância seguida do teste de Newman-Keuls quando todos os grupos foram comparados entre si e do teste de Dunnet quando os grupos foram comparados apenas com o grupo 
controle. O programa utilizado foi o GraphPad Prism ${ }^{\circledR}$ versão 5. (Motulski, 2007). 


\section{RESULTADOS}

“Desinventar objetos. O pente, por exemplo. Dar ao pente funções de não pentear. Até que ele fique à disposição de ser uma begônia."

Manoel de Barros 


\section{Melatonina desempenha efeito dual sobre a viabilidade}

\section{celular}

A viabilidade celular, avaliada através do ensaio do MTT, diminuiu em cerca de 20 - $40 \%$ quando as células foram incubadas com LPS (30 - 300 $\mathrm{ng} / \mathrm{mL}, 24 \mathrm{~h}$ ) como representado na figura $1 \mathrm{~A}$. Como esperado a melatonina em concentrações acima de $10 \mathrm{nM}(10 \mathrm{nM}-1 \mu \mathrm{M}, 24 \mathrm{~h})$ protegeram as células do efeito do LPS (100 ng/mL, 24 h), aumentando a sobrevivência das células (fig. 1B). Por outro lado, culturas de células de cerebelo incubadas apenas com melatonina (100 nM - $1 \mu \mathrm{M}, 24 \mathrm{~h})$ também sofreram uma redução da viabilidade em cerca de $20 \%$, sugerindo que na ausência de um estímulo injuriante, a melatonina per se apresenta um efeito citotóxico.

A

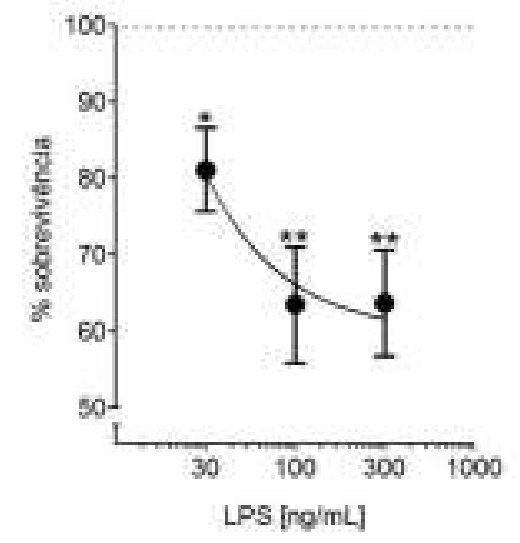

B

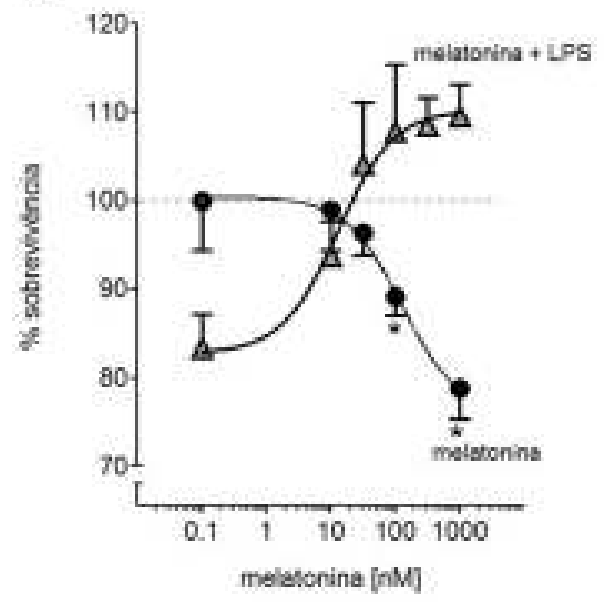

Figura 1 - Efeito dual da melatonina sobre a viabilidade de cultura de células de cerebelo. (A) Lipopolissacarídeo (30 - $300 \mathrm{ng} / \mathrm{mL}, 24 \mathrm{~h}$ ) induziu morte celular e (B) a melatonina (0,1 nM - $1 \mu \mathrm{M}, 24 \mathrm{~h})$ reverteu o efeito do LPS. Na ausência do LPS, altas concentrações de melatonina $(100 \mathrm{nM}-1 \mu \mathrm{M})$ também induzem morte celular. A viabilidade foi representada como porcentagem do controle. ${ }^{*} \mathrm{p}<0,05$ e ** $\mathrm{p}<0,01$ comparados ao grupo controle ( $\mathrm{n}=8-10$ por ponto). 


\section{Melatonina modula a via do fator de transcrição NF-kB}

Tendo em vista que a via do fator de transcrição NF-kB é um alvo comum tanto para a melatonina quanto para o LPS e que as células de cerebelo em cultura requerem uma atividade basal de NF-kB para a sobrevivência (Kaltschmidt et al., 2005), foi avaliado se este fator de transcrição, central nas respostas de defesa, poderia estar envolvido no efeito dual da melatonina sobre a sobrevivência celular.

O ensaio de gel-shift revela dois complexos que se ligam a sonda de NFКB (C1 e C2) (fig. 2). A incubação dos extratos nucleares com anticorpos para as subunidades do NF-kB de células previamente tratadas com LPS (100 ng/mL; 2 - 10 h) mostram que a expressão das subunidades variou ao longo do tempo. Com exceção da subunidade p52, todas as demais subunidades estão presentes na cultura não estimulada $(0 \mathrm{~h})$, como pode ser visto pelo deslocamento para a esquerda das curvas de análise densitométrica das subunidades p50, RelA, RelB e c-Rel. A incubação com LPS promove uma alteração dos dímeros presentes no núcleo. Após duas horas os anticorpos para p50, RelA e c-Rel induzem o supershift da marcação, deslocando para a esquerda as curvas de análise densitométrica, indicando a presença dessas subunidades no núcleo. Após quatro horas a RelB também está presente. E nos tempos de 6, 8 (dados não apresentados) e 10 horas a presença da subunidade p50 se torna dominante, pois desloca por completo os complexos. Enquanto isso, as subunidades RelA, RelB e c-Rel podem estar presente em uma quantidade menor que a p50. O 
anticorpo anti-p50 desloca ambos os complexos (C1 e C2), já os anticorpos antiRelA e anti-c-Rel deslocam apenas parcialmente o complexo 1 (C1), indicando que a subunidade p50 está presente em ambos os complexos e as demais subunidades apenas no complexo $\mathrm{C} 1$.

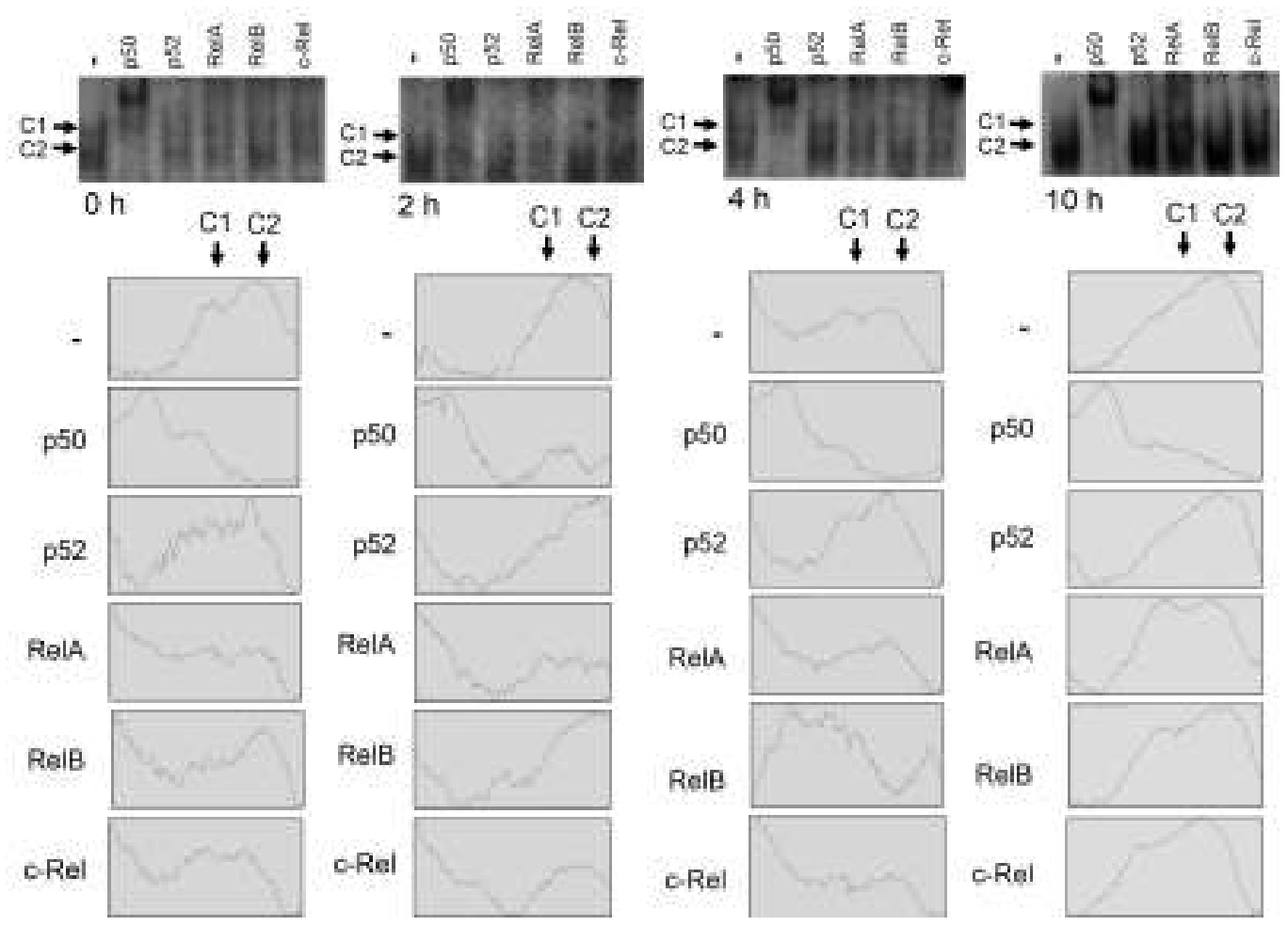

Figura 2 - Ensaio de super-shift para extratos nucleares de células de cerebelo em cultura. Culturas de células granulares de cerebelo foram estimuladas com LPS (100 $\mathrm{ng} / \mathrm{mL}, 0,2,4$ e $12 \mathrm{~h}$ ). Acima, autorradiogramas resultantes do EMSA revelando a presença de dois complexos DNA-NF- $\mathrm{B}$ (C1 e C2). Os anticorpos anti-p50, anti-RelA, anti-RelB e anti-c-Rel deslocaram os complexos, enquanto que o anticorpo anti-p52 não deslocou. Abaixo, as respectivas curvas da análise densitométrica obtidas através do programa ImageJ para cada coluna e para cada tempo.

Verificamos o efeito da incubação das culturas com 100 nM de melatonina e esta induziu uma redução transiente dos níveis nucleares dos 
dímeros que compõem os complexos C1 e C2 durante os primeiros 15 minutos (fig 3A). Após 30 minutos de incubação, o conteúdo nuclear de ambos os complexos foi restaurado para os valores iniciais; após 60 minutos de incubação o conteúdo nuclear do $C 2$, mas não do $C 1$, aumentou significativamente. Pelo fato da melatonina inibir a atividade do NF-kB já nos primeiros 15 minutos de incubação, foi utilizado este intervalo de tempo para construir uma curva doseresposta para a melatonina (fig. 3B). A máxima redução no conteúdo nuclear de NF-kB induzida pela melatonina $(40 \%)$ foi semelhante para ambos os complexos, entretanto, os níveis do primeiro complexo reduziram com concentrações menores de melatonina, indicando uma sensibilidade específica para os dímeros que compõem cada complexo. Desta forma, em cultura de células granulares de cerebelo a melatonina produziu uma redução transiente no conteúdo nuclear do NF- $\kappa B$, seguido de um aumento nos níveis do complexo que contém a principal subunidade indutora da expressão gênica (RelA).

A adição de LPS (100 ng/mL) aumentou significativamente o conteúdo nuclear do C1, enquanto que induziu uma redução do C2 (fig. 3C). A melatonina (10 nM - $1 \mu \mathrm{M})$ bloqueou a translocação nuclear dos dímero do $\mathrm{C} 1$, mas não interferiu no conteúdo do C2, apesar de haver uma tendência de aumento dos níveis desse complexo no núcleo para valores próximo ao basal quando se incubou com a maior concentração de melatonina utilizada $(1 \mu \mathrm{M})$. Portanto, na presença de LPS a melatonina reduz a translocação nuclear do NFкB. O efeito antagônico da melatonina observado na ausência ou na presença de 
LPS está de acordo com a sobrevivência celular apresentada na figura 1, ou seja, na ausência do LPS a melatonina induz morte celular e um aumento da translocação nuclear do NF-kB. Já na presença do LPS, a melatonina protege as células, reduzindo a atividade do NF-KB.

A

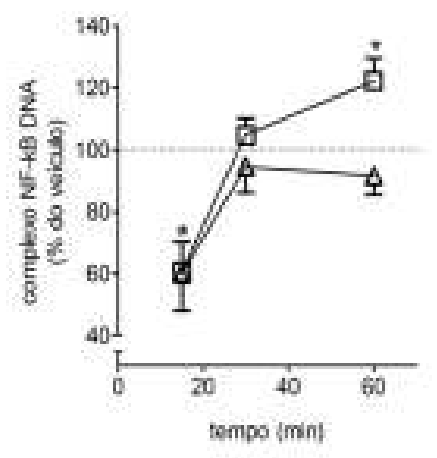

B

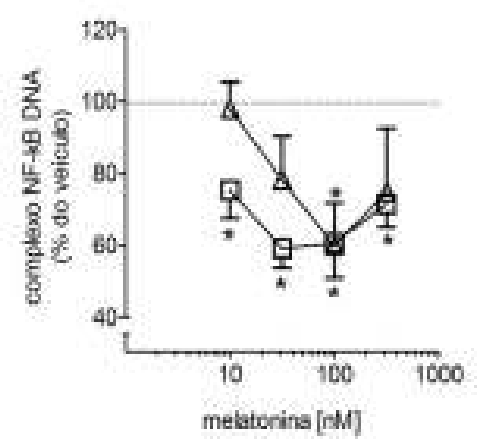

C

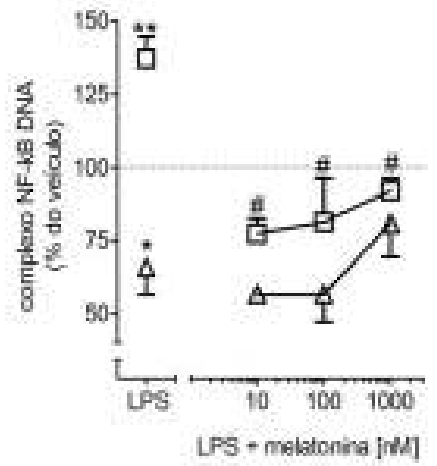

Figura 3 - Ativação do fator de transcrição NF-kB em cultura de células granulares de cerebelo. (A) Curva temporal de incubação com melatonina (100 nM) mostrando uma redução transiente no conteúdo nuclear dos complexos C1 e C2, seguido por um aumento significativo no conteúdo nuclear do complexo $\mathrm{C} 1$, que contém a subunidade RelA. (B) Curva dose-resposta para melatonina (10 nM - $1 \mu \mathrm{M} ; 15 \mathrm{~min})$. (C) Indução da translocação nuclear do NF-אB por LPS (100 ng/mL; 15 min.) na ausência ou presença de melatonina (10 $\mathrm{nM}-1 \mu \mathrm{M} ; 15 \mathrm{~min}$.). Os valores foram expressos como porcentagem do veículo $(100 \%)$. ${ }^{*}<0,05$ comparado ao veículo e \# $\mathrm{p}<0,05$ comparado ao LPS ( $\mathrm{n}=5$ -8 por ponto). Símbolos: quadrados $=\mathrm{C} 1$ e triângulo $=\mathrm{C} 2$.

\section{Expressão de iNOS}

Como medida da atividade do NF-kB foi avaliada a expressão da enzima iNOS através de imunocitoquímica. Neste caso, a quantificação da imunofluorescência foi feita somente nas células granulares, que foram 
identificadas pela morfologia, indicadas pelas setas pretas na figura 4 . Os outros tipos celulares, com morfologias diferenciadas como indicadas pelas cabeças de seta, não foram computadas. A expressão constitutiva da iNOS foi identificada no grupo controle (fig. 4A) e um aumento dessa expressão pode ser observado quando as células foram incubadas com LPS (100 ng/mL, 1 h) ou com melatonina (100 nM, 1 h) (figs. 4B, C, respectivamente). Na presença de ambos, LPS e melatonina (fig. 4D), é possível notar uma diminuição da fluorescência para níveis semelhantes ao do grupo veículo. A quantificação desse resultado está colocada na figura $5 \mathrm{~A}$, onde se observa que outras concentrações de melatonina (30 - 300 nM, 1h) também inibem a expressão da iNOS induzida por LPS.

O decurso temporal da expressão da enzima (fig. 5B) revela que a incubação com melatonina promove uma redução transiente do conteúdo de iNOS (30 min.) que é revertido para valores acima do basal após 120 minutos. Como esperado, o LPS aumenta a expressão de iNOS já nos primeiros 30 minutos, sendo que este efeito é bloqueado pela melatonina. Portanto, o efeito da melatonina na expressão da iNOS segue mesmo perfil descrito para a atividade do NF-kB. 

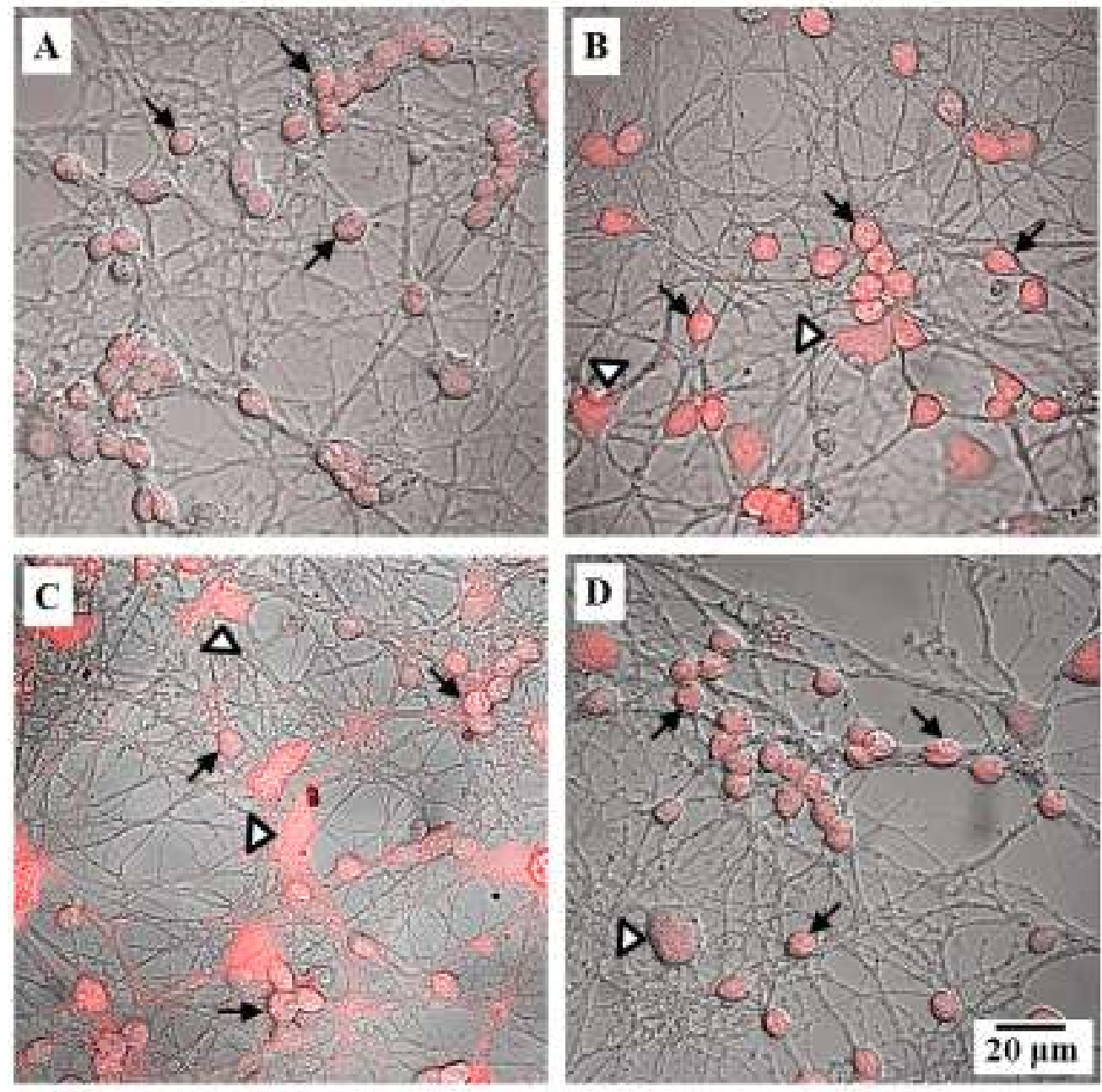

Figura 4 - Imagem de confocal representativa da imunocitoquímica para a expressão de iNOS. (A) Veículo. (B) Incubação com $100 \mathrm{nM}$ de melatonina. (C) incubação com 100 ng/mL de LPS. (D) incubação com melatonina + LPS. O tempo de incubação foi de 60 minutos. Setas pretas indicam células granulares e cabeças de setas brancas indicam células da glia. 
A

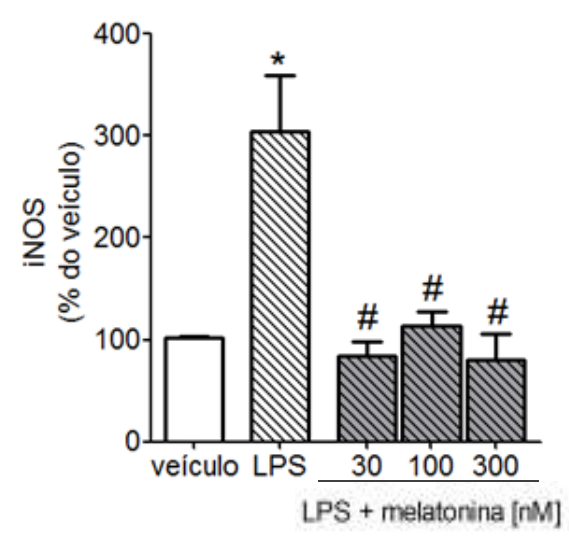

B

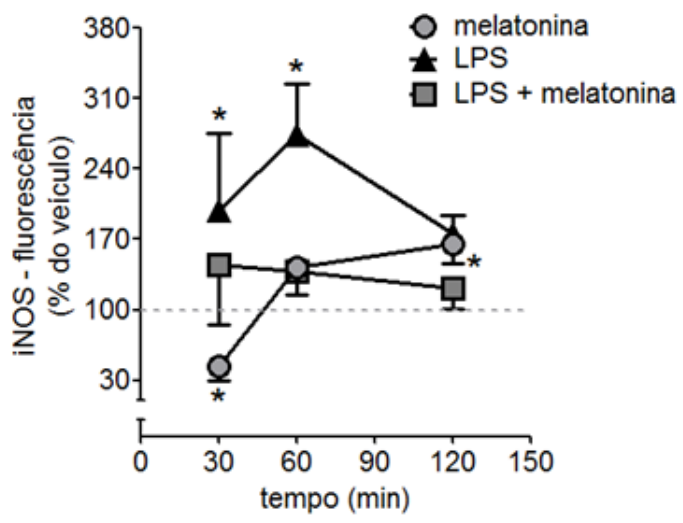

Figura 5 - Quantificação da expressão de iNOS. (A) LPS (100 ng/mL, $60 \mathrm{~min}$.) induziu a expressão de iNOS na ausência ou presença de melatonina (30 - $300 \mathrm{nM}, 60 \mathrm{~min}$.) (B) Curvas temporais de incubação com melatonina (100 nM), LPS (100 ng/mL) ou melatonina + LPS. * $\mathrm{p}<0,05$ e ${ }^{* *} \mathrm{p}<0,01$ comparados ao veículo e \# $\mathrm{p}<0,05$ comparado ao LPS ( $\mathrm{n}=4-6$ experimentos por ponto).

\section{Aumento de óxido nítrico induz morte celular}

Como resultado do aumento da expressão da iNOS, a incubação com LPS induziu um aumento do conteúdo intracelular de NO. Tal como descrito para a expressão da iNOS, a melatonina apresentou um efeito dual sobre a produção de NO. Quando incubada concomitantemente ao LPS reduz a produção de NO, mas quando incubada isoladamente em culturas sem LPS induz um aumento da produção deste gás (fig. 6A). Para testar se a morte celular provocada pela incubação com melatonina estava relacionada ao aumento da expressão da iNOS, a atividade desta enzima foi bloqueada pelo inibidor 1400W. A redução da viabilidade induzida pelo LPS (100 ng/mL, 24 h) ou pela melatonina (100 nM, 24 h) é revertida pela presença do inibidor. Além 
disso, o bloqueio da atividade da iNOS aumenta a sobrevivência dos grupos veículos, corroborando a constatação anterior de que há uma atividade basal de iNOS (fig. 6B, C).

A

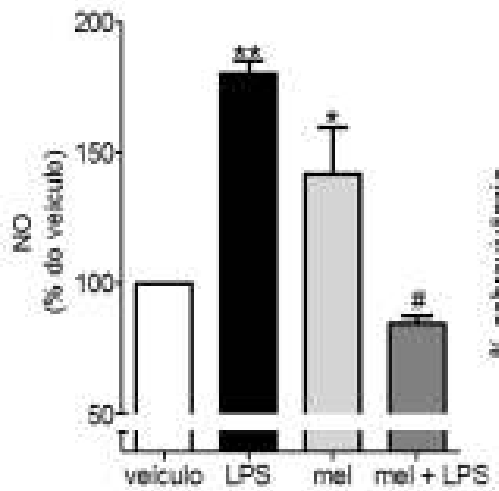

B

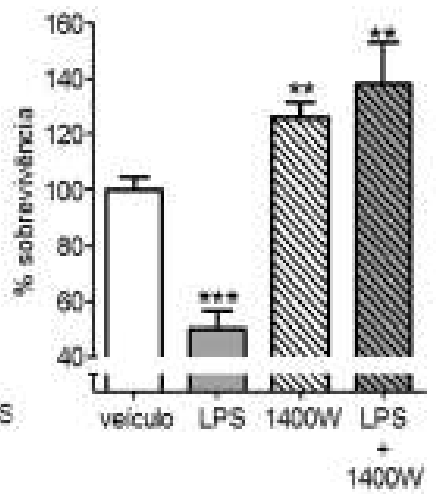

c

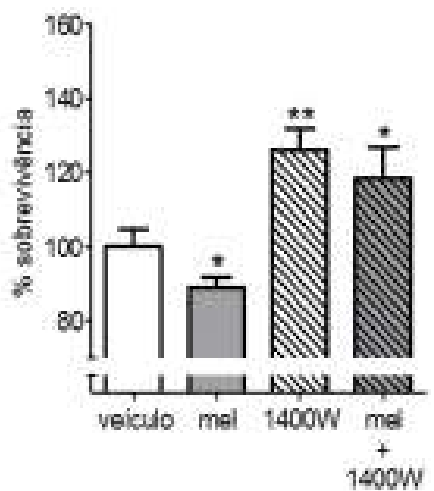

Figura 6 - A produção de óxido nítrico é responsável pela indução de morte celular na presença de melatonina e LPS. (A) Quantificação da produção de NO em culturas de células granulares de cerebelo incubadas com LPS (100 ng/mL, 24 h), melatonina (100 nM, 24 h) ou melatonina+ LPS. (B,C) Efeito do inibidor específico da atividade da iNOS $(1400 \mathrm{~W}, 1 \mu \mathrm{M})$ na sobrevivência de células granulares de cerebelo em culturas incubadas com LPS (100 ng/mL, $24 \mathrm{~h})$ ou melatonina $(100 \mathrm{nM}, 24 \mathrm{~h})$, respectivamente. * $\mathrm{p}<0,05 \%,{ }^{* *} \mathrm{p}<0,01 \mathrm{e}^{* * *} \mathrm{p}<0,001$ comparados ao controle e \# $\mathrm{p}<0,05$ comparado ao LPS ( $\mathrm{n}=3$ por ponto).

\section{Células granulares do cerebelo em cultura expressam AA-}

\section{NAT e produzem melatonina}

Além da função da melatonina exógena sobre a viabilidade das células granulares de cerebelo, investigamos se essas células são capazes de produzir melatonina, tendo em vista que a produção dessa indolamina foi detectada no 
cerebelo de ratos que receberam injeção intracerebroventricular (i.c.v.) de LPS (Pinato et al., 2013). A expressão da enzima chave na síntese de melatonina, AANAT foi detectada por imunocitoquímica. Células granulares de cerebelo expressam AA-NAT em condição basal (fig. 7A, B) e o estímulo com LPS (100 ng/mL; $2-6$ h) aumenta em cerca de $100 \%$ a expressão da enzima (fig. 7A, C). A quantificação da fluorescência foi feita somente em células granulares (setas pretas) que foram diferenciadas por sua morfologia e tamanho. Células com morfologias diferenciadas (cabeças de setas) não foram contabilizadas (fig. 7B, C).
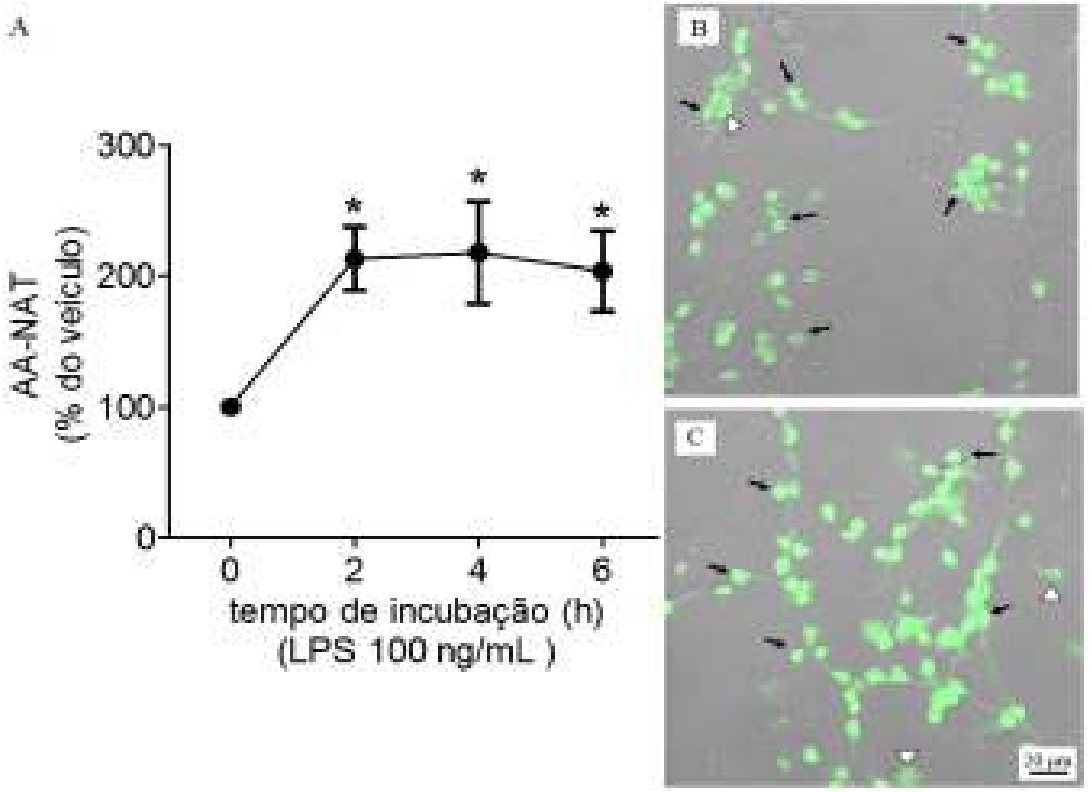

Figura 7 - Expressão de AA-NAT em células granulares de cerebelo. (A) LPS (100 ng/mL, $2-6 \mathrm{~h}$ ) induz aumento da expressão de AA-NAT em células granulares de cerebelo. (B, C) Imagens representativas evidenciando (B) a expressão basal de AANAT e (C) o aumento da expressão da enzima em células tratadas com LPS (100 $\mathrm{ng} / \mathrm{mL}, 2 \mathrm{~h}$ ). As setas pretas indicam as células granulares que foram computadas na quantificação da imunofluorescência. As cabeças de setas brancas apontam para células com morfologias diferenciadas (células da glia) e que não foram computadas neste estudo. ${ }^{*} \mathrm{p}<0,05$ comparado ao controle, ( $\mathrm{n}=3$ por ponto). 
Células cerebelares em cultura sintetizam melatonina que é detectada no meio de cultura em condição basal (veículo) (fig. 8). Quanto maior o tempo de cultivo, maior é a concentração encontrada, ou seja, após 6 horas de incubação com veículo foi dosada uma média de 7,30 $\pm 3,80$ pg/mL e após 12 horas 18,22 \pm 1,88 pg/mL. Apesar do aumento da expressão da AA-NAT após incubação com LPS se dar nas primeiras horas de incubação, o LPS (30 ng/mL - $1 \mu \mathrm{g} / \mathrm{mL})$ estimula um aumento da síntese de melatonina que é estatisticamente significativo após 12 horas, mas não em tempos anteriores, como pode ser observado após 6 horas de incubação (fig. 8).

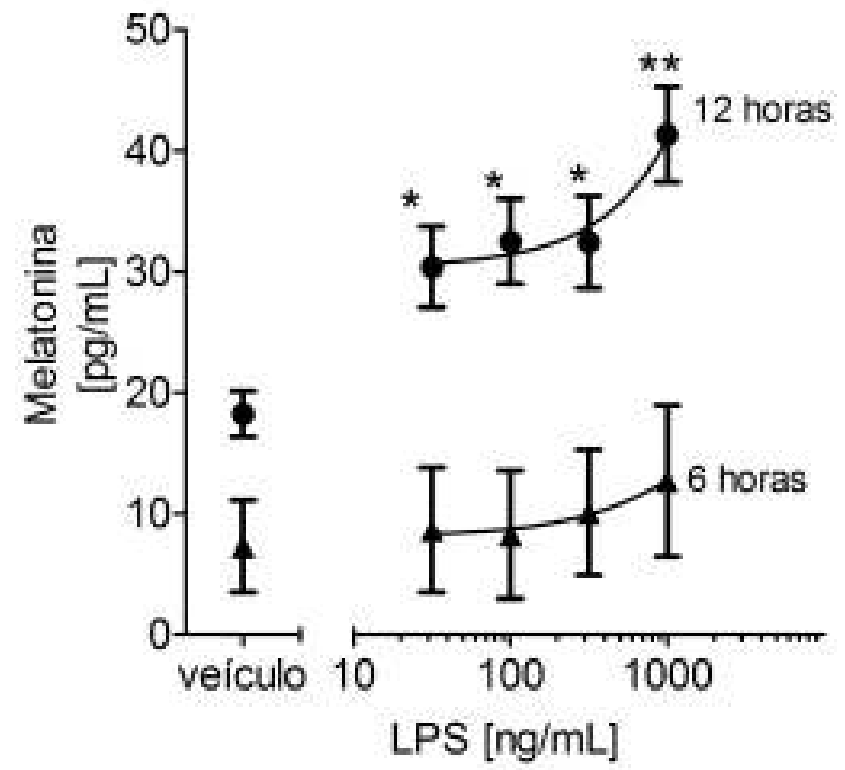

Figura 8 - Dosagem de melatonina em meio de cultura de células de cerebelo. Células de cerebelo em cultura em condição basal (veículo) produzem melatonina. $\mathrm{O}$ tratamento com LPS $(100 \mathrm{ng} / \mathrm{mL})$ por 12 horas aumenta significativamente a produção de melatonina. ${ }^{*} \mathrm{p}<0,05 \mathrm{e}$ ** $\mathrm{p}<0,01$ comparados ao veículo; $\mathrm{n}=6$ para grupo de 12 horas e $\mathrm{n}=3$ grupo de 6 horas. 


\section{Melatonina endógena protege as células do cerebelo da}

\section{morte celular induzida por LPS}

O LPS (30 ng/mL) reduz em cerca de $20 \%$ a viabilidade da cultura de células granulares de cerebelo. O bloqueio de receptores de melatonina por luzindol $(100 \mathrm{nM})$ potencia a morte celular induzida por LPS em cerca de $45 \%$ em relação ao veículo (Fig. 9), indicando, portanto, que a melatonina produzida localmente faz parte da manutenção da viabilidade celular frente a estímulo tóxico.

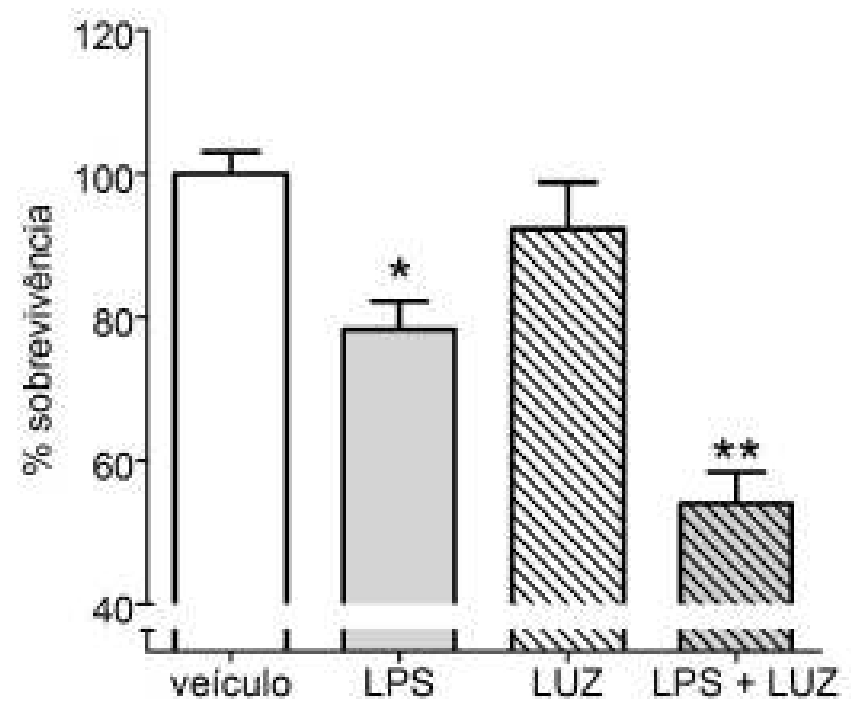

Figura 9 - A melatonina produzida pela cultura de células granulares de cerebelo incubadas com LPS tem papel protetor. Viabilidade celular de cultura de células granulares de cerebelo tratadas com LPS (30 ng/mL, 24 h) na ausência ou presença de luzindol (100 nM, 24 h). * $\mathrm{p}<0,01 \mathrm{e}{ }^{* *} \mathrm{p}<0,001$ comparados ao veículo $(\mathrm{n}=3)$. 


\section{DISCUSSÃO}

"A ciência nunca resolve um problema sem criar pelo menos outros dez"

George Bernard Shaw 
Muitos trabalhos da literatura apoiam o papel da melatonina como agente de proteção em diferentes tipos celulares e tecidos, agindo por mecanismos dependentes ou independentes de receptores de membrana (Luchetti et al., 2010). No presente estudo demonstramos que a melatonina pode exercer um efeito dual sobre a viabilidade de células granulares de cerebelo em cultura dependendo do contexto em que essas células se encontram. Na presença de LPS a melatonina protege as células inibindo a ativação da via do NF-кB. No entanto, a incubação apenas com melatonina gera um efeito citotóxico que resulta em morte celular. Este resultado pode ser comparado ao efeito da melatonina sobre células cancerosas em que se observa um aumento de ROS e moléculas pró-apoptóticas (Sainz et al., 2003).

Este efeito ambíguo da melatonina pode envolver a via do fator de transcrição NF-kB. A dualidade do papel do NF-kB no sistema nervoso foi discutida em uma revisão feita por Kaltschmidt e colaboradores (2005), na qual se propõe que o gráfico da relação entre a sobrevivência celular (utilizando modelo de cultura de células granulares) e a atividade do NF-kB segue uma curva em sino. Isso quer dizer que tanto uma baixa, quanto uma alta ativação do NF-kB pode induzir morte, sendo que existe uma faixa de ativação ótima para a sobrevivência celular. Neste trabalho demonstramos que a melatonina interfere no balanço basal do NF-kB nas células granulares do cerebelo em cultura, resultando em morte celular. Por outro lado, a melatonina compensa o aumento da atividade deste fator de transcrição induzido por LPS, proporcionando uma condição favorável à viabilidade celular. 


\section{Efeitos citoprotetores da melatonina - integração do cerebelo}

\section{ao eixo Imune-Pineal}

O papel citoprotetor da melatonina se dá por diferentes mecanismos associados à redução de agentes que favorecem a inflamação, o estresse oxidativo ou a morte celular (Luchetti et al., 2010). Em cultura de células granulares de cerebelo, confirmamos que LPS induz a expressão de iNOS e a produção de NO (Sato et al., 1995; 1996) e corroboramos diversos resultados que demonstram os efeitos benéficos da melatonina sobre a inibição da atividade do NF-kB em modelos in vivo (Bruck et al., 2004; Alonso et al., 2006; Tripathi e Jena, 2010; Bekyarova et al., 2012) e in vitro (Gilad et al., 1998; Tamura et al., 2009; Min et al., 2012).

Um dos efeitos da redução da atividade do NF-kB é a diminuição da expressão da enzima iNOS e de seu produto, NO. O NO é um importante neuromodulador que tem uma baixa reatividade, contudo, forma RNS $\left(\mathrm{NO}_{2}\right.$, $\mathrm{N}_{2} \mathrm{O}_{3}$ e ONOO-) capazes de modificar biomoléculas que participam de processos fisiológicos (Calabrese et al., 2009). O excesso da produção de RNS em resposta à uma inflamação pode estar associado à neurodegeneração (Bishop e Anderson, 2005). A melatonina tem efeitos benéficos sobre o estresse oxidativo envolvendo a produção de NO por reduzir a atividade da isoforma iNOS, cuja expressão é dependente da atividade de NF-kB, conforme demonstrado em cérebro isquêmico (Kaur et al., 2006; Koh, 2008) e em doenças neurodegenerativas (Ortiz et al., 2008; Negi et al., 2011). 
Embora muitos dos efeitos protetores da melatonina e de seus metabólitos estejam associados com a ação antioxidante (Galano et al., 2011; 2013), o envolvimento dos receptores $\mathrm{MT}_{1}$ e $\mathrm{MT}_{2}$ também está descrito em modelos de sepse, apoptose e neurodegeneração (Husson et al., 2002; Radogna et al., 2007; Imbesi et al., 2008; Fink et al., 2014; Wang et al., 2013). Na cultura de células granulares de cerebelo de camundongo Imbesi e colaboradores (2008) mostraram que o efeito da melatonina de inibir o aumento de c-fos induzida por forscolina depende da presença dos dois receptores de melatonina. Células originárias de camundongos com deleção de um dos receptores perdem o efeito positivo da melatonina. Nossos resultados mostram que o bloqueio de receptores de melatonina pelo antagonista luzindol gera um aumento na morte celular induzida por LPS. Este resultado indica que essa cultura produz melatonina que age, de forma parácrina, através de receptores de membrana das células. Este resultado foi confirmado in vivo pelo bloqueio de receptores de melatonina com injeção i.c.v. de luzindol, o que leva a um aumento no efeito neurotóxico do LPS no cerebelo (Pinato et al., 2013).

A hipótese do eixo Imune-Pineal preconiza que na fase inicial de uma inflamação a glândula pineal deixa de produzir melatonina, abolindo, portanto, o ritmo plasmático do hormônio. Este evento é importante para que a resposta inflamatória dos leucócitos seja iniciada. Já na fase de resolução, células imunocompetentes passam a produzir melatonina em altas concentrações no local da lesão. Neste cenário a melatonina age como anti-inflamatória e antioxidante (Markus e Ferreira, 2011). No presente trabalho demonstramos 
que células granulares de cerebelo em cultura expressam a enzima-chave na síntese de melatonina (AA-NAT) que pode ser correlacionada com a produção basal de melatonina. Apesar do LPS induzir um aumento da expressão da enzima após duas horas de incubação, o aumento na produção de melatonina só foi detectado após doze horas de incubação.

A síntese de melatonina pode ser modulada pela atividade do NF-kB (Cecon et al., 2010; Muxel et al., 2012; Pires-Lapa et al., 2013) sendo que em linhagens de macrófagos RAW 264.7 a expressão da AA-NAT é induzida por dímeros de NF-kB que contém as subunidades RelA e c-Rel (Muxel et al., 2012). Em experimento in vivo, a injecção intraperitoneal de pirrolidina ditiocarbamato (PDTC - inibidor da atividade do NF-kB), duas horas antes da injeção i.c.v de LPS, inibe a indução da síntese de melatonina no cerebelo (Pinato et al., 2013). Com base nesses dados, levantamos a hipótese de que em cultura de células granulares de cerebelo a produção de melatonina dependeria da atividade do NF-kB, mais especificamente, da ativação de dímeros contendo RelA e c-Rel, lembrando que estas subunidades contém TAD na região c-terminal necessária para indução da transcrição gênica (Xiao, 2004).

A análise da atividade do NF-kB nos mostra que os dois complexos (C1 e C2) presentes nos autorradiogramas são compostos por dímeros formados por p50, RelA, RelB e c-Rel sendo que a subunidade p50 está presente em ambos os complexos e as subunidades RelA e c-Rel no complexo 1 (C1). A incubação com LPS (2 - $10 \mathrm{~h})$ induz uma ativação de diferentes subunidades em cada tempo analisado. Nas primeiras duas horas estão presentes as subunidades p50, RelA 
e c-Rel. Rao e colaboradores (2010) descreveram a presença de dímeros formados por essas mesmas subunidades após estímulo com LPS em células embrionárias de camundongo. Após quatro horas de incubação com LPS, a subunidade RelB também está presente no núcleo das células granulares de cerebelo. Os dímeros formado por RelA, RelB e c-Rel são capazes de ativar a transcrição gênica por conterem o domínio TAD (Xiao, 2004). Tempos maiores (6 - 10 h) revelam que a atividade da subunidade inibitória da transcrição gênica, p50, é prevalecente. A atividade do NF-kB ocorre de forma oscilatória, ou seja, um mesmo estímulo é capaz de gerar ondas de atividade de diferentes dímeros de NF-kB que resultam na expressão ou inibição de diferentes genes em cada momento. (Nelson et al., 2004; Turner et al., 2010). Isso é possível porque o NF-kB é capaz de regular a expressão da proteína inibitória IкBa (Hayden e Ghosh, 2004). A presença das subunidades RelA e c-Rel coincide com o tempo de expressão da AA-NAT (2 h), sugerindo que estas subunidades podem ser responsáveis pela expressão da enzima. Os resultados do bloqueio da atividade do NF-kB com PDTC não são conclusivos e, por isso, não foram apresentados neste trabalho

A expressão da enzima AA-NAT no sistema nervoso central é conhecida em células da glia (Stefulj et al., 2001; Liu et al., 2007; Park et al., 2010; Pinato et al., 2013), indicando que essas células contribuem com os níveis de melatonina encontrada no líquido cefalorraquidiano (Tan et al., 2010). No entanto, nossos resultados sugerem que os neurônios também sintetizam melatonina, já que expressam AA-NAT. Outra possibilidade é que os neurônios produzam NAS 
que, além de ser precursora da melatonina e produto direto da atividade da AA-NAT (Simonneuax e Ribelayga, 2003), tem uma distribuição própria e diferente da melatonina no sistema nervoso central, sugerindo que essa molécula tenha um papel distinto (Paul et al., 1974; Psarakis et al., 1982; Gaudet et al., 1991; Chae et al., 1999; Tosini et al., 2012b). A NAS pode ter um papel protetor contra o estresse oxidativo devido às suas propriedades antioxidantes (Oxenkrug, 2005), agindo diretamente sobre os radicais livres ou através de receptores $\left(\mathrm{MT}_{1}\right.$ e $\left.\mathrm{MT}_{2}\right)$, porém com menor afinidade que a melatonina ou, ainda, através do receptor do fator neurotrófico derivado do cérebro (BDNF), TrkB (Jang et al., 2010). Sendo assim, podemos inferir que em células granulares de cerebelo o aumento da expressão da AA-NAT induzido por LPS estaria relacionado à produção de NAS que poderia ou não ser convertida em melatonina. Isso pode explicar o atraso na síntese de melatonina em relação à expressão da AA-NAT induzidas pelo LPS.

\section{Efeitos citotóxicos da melatonina}

A morte de células granulares de cerebelo em cultura induzida pela melatonina pode ser um efeito sobre a atividade do NF-kB. Os resultados do presente trabalho indicam que a melatonina reduz de forma transiente a translocação nuclear do NF-kB e, após 60 minutos de incubação, a melatonina passa a aumentar a translocação nuclear desse fator de transcrição. Este efeito pode ser correlacionado à expressão da iNOS. A incubação com melatonina 
levou a uma queda transiente nos níveis de iNOS, seguido de um aumento na expressão dessa enzima. Após 24 horas de incubação com melatonina as células sofreram uma diminuição da viabilidade, o que poderia ser correlacionada ao aumento dos níveis de NO acima do valor do controle. Essa hipótese foi comprovada ao se bloquear a atividade da iNOS com o inibidor seletivo 1400W. A morte celular induzida por melatonina foi inibida na presença deste composto, sugerindo a participação do NO na redução da viabilidade celular. Tanto a melatonina quanto o LPS induziram morte celular apenas 24 horas após início da incubação. Tempos menores não foram suficientes para reduzir a viabilidade, indicando que o tipo de morte celular nestes dois casos foi a apoptose (Grivicichi et al., 2007).

A melatonina como molécula pró-apoptótica tem sido caracterizada basicamente em células cancerosas (Sainz et al., 2003). A morte celular por apoptose é um fenômeno fisiológico associado à homeostase e uma falha no programa de apoptose pode ocasionar doenças auto-imunes e câncer (Grivicich et al., 2007). A melatonina tem a capacidade de induzir apoptose em células cancerosas por ativar a produção de ROS e vias pró-apoptóticas através da modulação da atividade do NF-kB, reduzindo o crescimento tumoral (Sainz et al., 2003; Cristofanon et al., 2009; Radogna et al., 2009; Bejarano et al., 2011; Lanoix et al., 2012). Em um modelo celular de câncer de próstata humano (LNCaP), por exemplo, a melatonina potencia a morte celular induzida por TNF ou radiação gama ao inibir a atividade do NF-kB, elevando a capacidade antioxidante das células (Sainz et al., 2008). Resultado semelhante foi 
demonstrado em células pró-mielocíticas leucêmicas de humano (HL-60) em que a melatonina potencia os efeitos do peróxido de hidrogênio, levando as células à apoptose (Bejarano et al., 2011). Em outro caso, linhagens de células tumorais promonocíticas humana o efeito pró-oxidante da melatonina se dá através do aumento da translocação nuclear do dímero de NF-kB p50/RelA (Cristofanon et al., 2009).

$\mathrm{O}$ aumento da atividade do NF-kB induzido por melatonina pode ser explicado por duas alternativas. A primeira se refere à interação da melatonina com o receptor órfão RORa, como proposto por Tomás-Zapico e Coto-Montes (2005). Este receptor órfão induz a expressão da proteína inibitória IKB, regulando negativamente a atividade do NF-kB. Ao inibir direta ou indiretamente (via calmodulina) a atividade do RORa a melatonina promove um aumento da atividade do NF-kB.

A segunda maneira pela qual a melatonina poderia elevar os níveis deste fator de transcrição seria através de uma alça de retroalimentação entre a

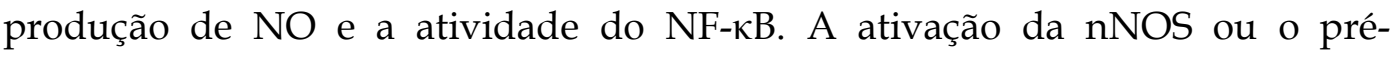
tratamento com doares de NO são capazes de inibir a translocação nuclear do NF-кB induzido por LPS ou TNF (Park et al., 1994; Peng et al., 1995; Colasanti et al., 1995; Togashi et al., 1997). Os mecanismos subjacentes envolvem nitrosilação

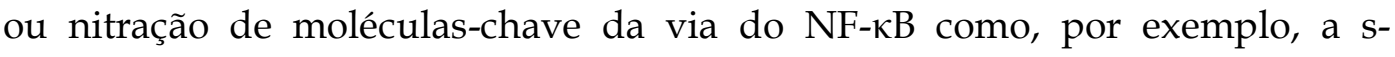
nitrosilação da proteína IKK que leva à inibição da atividade do NF-KB (Reynaert et al., 2004). Além disso, a nitração da tirosina da RelA mantém esta subunidade no citoplasma (Park et al., 2005) e a s-nitrosilação da p50 impede a 
ligação do homo ou do heterodímero ao DNA (Mathews et al., 1996, delaTorre et al., 1999). O NO também induz a expressão e estabiliza a proteína inibitória IkBa (Peng et al., 1995). A redução do nível basal de NO abaixo de um valor crítico favorece a ativação do NF-kB, levando a um aumento subsequente da expressão da iNOS e da produção de NO. Sendo assim, nossos resultados

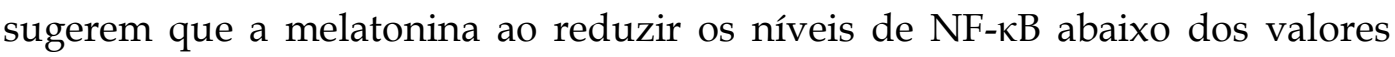
basais, diminui a expressão de iNOS e de NO suficiente para induzir uma

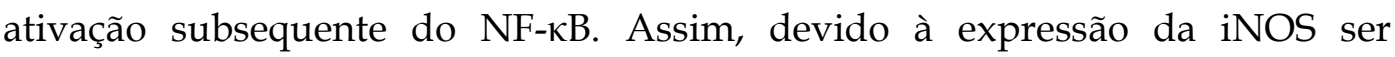

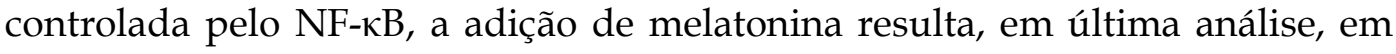
um aumento da expressão de iNOS e da produção de NO que levam à morte celular. Esta hipótese é reforçada pelo resultado da expressão da iNOS na presença de melatonina em que se observa, em um primeiro momento, uma diminuição em relação ao controle, seguida de um aumento na expressão da enzima.

A melatonina liberada na corrente sanguínea pela glândula pineal faz parte da temporização endógena que sincroniza o organismo ao ciclo claro/escuro ambiental. Em diversas doenças como demências, transtornos do humor, dores crônicas, distúrbios do sono, câncer e diabetes os níveis de melatonina plasmática estão reduzidos e, nestes casos, essa indolamina tem sido considerada uma ferramenta terapêutica interessante (Hardeland, 2012). Além disso, o uso dessas propriedades cronobióticas tem sido descrita com sucesso em casos de distúrbios do sono associados ao jetlag, trabalho em turnos, síndrome do atraso na fase de sono e transtornos do sono em idosos (Arendt e 
Skene, 2005). Nos Estados Unidos a melatonina é classificada como suplemento alimentar e, portanto, é vendida sem necessidade de prescrição médica. No Brasil a venda de melatonina para fins terapêuticos não é permitida pela Agência Nacional de Vigilância Sanitária (ANVISA) por não possui registro e eficácia terapêutica avaliada pela agência.

Pouco se sabe sobre os efeitos adversos do uso da melatonina quanto à concentração, tempo de tratamento ou o uso em indivíduos sadios. Em um estudo toxicológico com indivíduos saudáveis (10 mg diário por 28 dias), por exemplo, não houve alteração nos níveis eletrolíticos, nas funções renal, hepática, da tireóide, da glândula adrenal ou mesmo na produção endógena de melatonina. Apesar disso, houve uma alteração no estágio 1 do sono nos indivíduos que tomaram melatonina e um número maior desses indivíduos em relação aos que tomaram placebo relataram maior sonolência e dor de cabeça (Seabra et al., 2000).

Um efeito negativo da aplicação farmacológica da melatonina foi observado na aquisição de memória em Danio rerio, conhecido como peixe paulistinha, um animal de hábito diurno (Rawashdeh et al., 2007; Rawashdeh e Maronde, 2012). Neste modelo, a consolidação da memória é facilitada na fase de claro e a melatonina aplicada farmacologicamente nesta fase tem um efeito inibitório no aprendizado de novas tarefas. A melatonina, no entanto, não tem efeito na memória já consolidada. Em ratos, a melatonina administrada durante a fase de claro prejudica a formação de memória vísuo-espacial (Soto-Moyano et al., 2006) e em fatias de hipocampo de camundongo a melatonina prejudica a 
potenciação de longo prazo, provável mecanismo pelo qual a memória é codificada e armazenada no SNC. Este efeito parece depender de receptores $\mathrm{MT}_{2}$ (Wang et al., 2005) e da participação de NO, uma vez que a administração de um doador de NO bloqueia o efeito inibitório da melatonina na potenciação de longo prazo (Takahashi e Okada, 2011). Em humanos, não há estudos que demonstrem os efeitos da melatonina na memória de sujeitos saudáveis.

Um outro exemplo do efeito negativo da melatonina aplicada farmacologicamente se dá na retina. A retina sintetiza melatonina na fase de escuro e é necessário que os níveis de melatonina estejam baixo durante o dia, já que a melatonina potencia o dano oxidativo e a morte de fotorreceptores induzidos pela luz (Wiechmann e O'Steen, 1992). Apesar do uso da melatonina ser um recurso para o tratamento de glaucoma, por exemplo, a administração dessa indolamina na fase de claro pode induzir morte células de fotorreceptores (Tosini et al., 2012a). Os mecanismos pelos quais a melatonina aumenta a susceptibilidade da retina à luz ainda são desconhecidos (Sakamoto et al., 2004).

\section{Considerações finais}

A escolha da cultura de células granulares de cerebelo foi fundamental para a realização deste trabalho pois estas células apresentam uma atividade basal de NF-kB que é essencial para a sobrevivência em cultura. A melatonina foi capaz de alterar o conteúdo nuclear basal de NF-кB, o que provocou um aumento da expressão de iNOS e morte das células. Por outro lado, a 
administração de melatonina em culturas desafiadas por LPS promoveu um

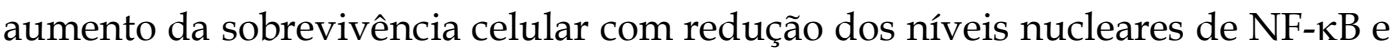
expressão de iNOS.

A cultura de células granulares de cerebelo produz melatonina em condição basal, com aumento dessa produção quando as células são estimuladas por LPS e o fato dos neurônios (células granulares) expressarem AA-NAT é um forte indício que essas células são capazes de produzir melatonina. Os resultados obtidos neste projeto e as colaborações com outros projetos nos permite inferir que o cerebelo é uma região protegida do sistema nervoso central graças à produção local de melatonina. Atuando de forma parácrina ou autócrina através de seus receptores de membrana protege as células do cerebelo dos efeitos neurotóxicos do LPS. Essa resposta parece ser uma exclusividade do cerebelo, já que não foi observada no córtex e no hipocampo de ratos injetados com LPS i.c.v. (Pinato et al., 2013).

A figura 10 mostra um esquema incluindo os resultados obtidos neste trabalho, as hipóteses levantadas e dados da literatura que elucidam o efeito dual da melatonina sobre a viabilidade das células granulares de cerebelo, dependendo do contexto em que se encontram e, levando em consideração, principalmente, a via do fator de transcrição NF-kB. Nossos resultados indicam um mecanismo pelo qual a melatonina poderia induzir morte celular em células normais. 


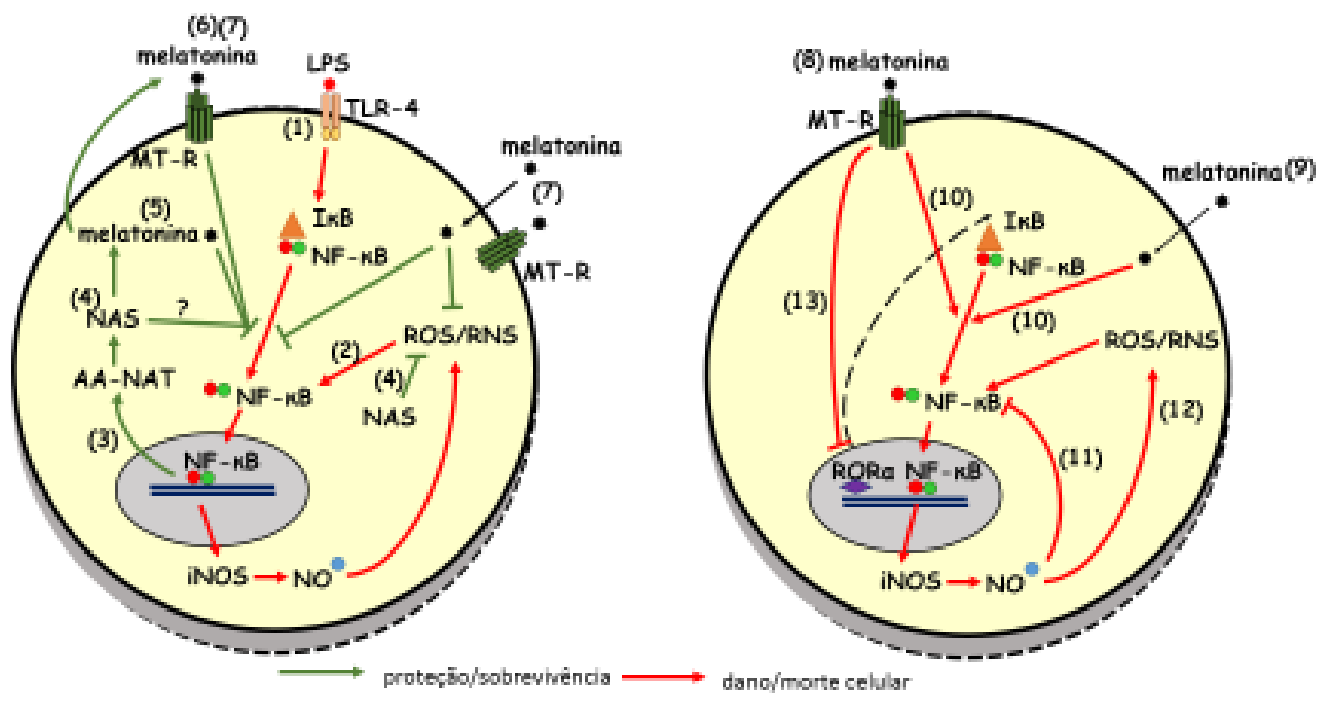

Figura 10 - Esquema hipotético para a atividade dual da melatonina em células granulares de cerebelo. À esquerda, células ativadas por LPS (1) através de seu receptor TLR-4 que leva a ativação da via do NF-кB. Uma vez ativado o NF-kB induz a expressão da iNOS que aumenta os níveis de NO. Este eleva os níveis de ROS/RNS (2) que também aumentam a atividade do NF-KB. A ativação deste fator de transcrição pode estar relacionada a ativação da expressão da AA-NAT (3) que catalisa a síntese de NAS (4). Esta poderia agir na via do NF-кB, interagir com ROS/RNS ou dar origem a melatonina (5). A melatonina produzida endogenamente pode ter uma ação autócrina (5) ou parácrina, agindo em seus receptores de membrana (MT-R) (6). A melatonina exógena ou proveniente de outras fontes, como a microglia e própria pineal, também age sobre receptores ou pode atravessar a membrana e interagir com a via do NF-kB e ROS/RNS (7). À direita, células tratadas somente com melatonina. A melatonina age nos receptores (8) ou atravessa a membrana celular (9), levando a uma redução transiente da atividade do NF-kB (10) o que reduz os níveis de NO na célula. Esta redução gera uma resposta de retroalimentação que induz um aumento da atividade do NF-KB (11). O aumento de ROS/RNS pode ser uma via adicional no aumento da atividade do NF-kB que eleva ainda mais os níveis de NO (12). Outra interação da melatonina é com o RORa (13). Este é responsável pelo aumento da expressão do IkB. Logo, o bloqueio da melatonina sobre RORa gera um aumento da atividade do NF-kB. 


\section{CONCLUSÕES}

"Se queremos progredir, não devemos repetir a história, mas fazer uma história nova"

Mahatma Gandh 
1. Melatonina desempenha efeito dual sobre a viabilidade celular dependendo do contexto: protegendo as células dos efeitos neurotóxicos causados pelo LPS ou induzindo morte celular em células não tratadas.

2. Em condição basal as células granulares de cerebelo apresentam dois complexos (C1 e C2) formados por dímeros que contém p50, RelA, RelB e c-Rel;

3. O LPS induz a ativação de diferentes subunidades do NF-kB ao longo do tempo;

4. A melatonina inibe a translocação nuclear do NF-kB, bem como reduz a expressão da iNOS e a produção de NO induzidos por LPS;

5. Em condição basal a melatonina induz uma redução transiente do NFкB, seguida de um aumento dos níveis nucleares do fator de transcrição;

6. Nesse contexto, a melatonina induz a expressão da iNOS e a produção de NO;

7. O aumento de NO está envolvido na morte celular induzida tanto pelo LPS quanto pela melatonina;

8. Células granulares do cerebelo em cultura expressam AA-NAT e produzem melatonina;

9. Melatonina endógena protege a cultura de células do cerebelo da morte celular induzida por LPS. 
RESUMO 


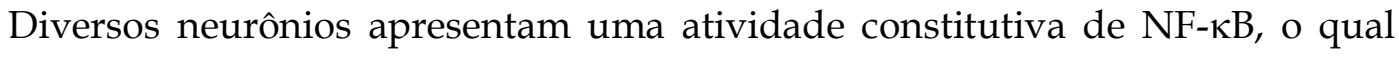
desempenha múltiplas funções fisiológicas, além da modulação de respostas patológicas. A melatonina, hormônio produzido ritmicamente pela glândula pineal na fase de escuro, é também um fator autócrino e parácrino envolvido em múltiplos processos biológicos, sendo que a citoproteção é uma ação de

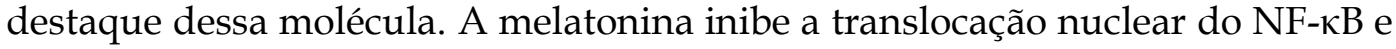
a expressão do seu produto iNOS em modelos de danos celular. No presente trabalho avaliamos se o efeito citoprotetor da melatonina depende do estado de ativação do NF-кB em cultura de células granulares de cerebelo, tendo em vista que essas células apresentam uma atividade basal deste fator de transcrição fundamental para a sobrevivência das células. Além disso, questionamos se essas células em cultura produziriam melatonina e se esta teria algum papel citoprotetor. Testamos a viabilidade da cultura de células granulares de cerebelo de rato (Wistar 7-8 dias de idade) após 24 horas de incubação com melatonina na presença ou ausência de LPS. Em condição basal a melatonina diminuiu a sobrevivência das células e inibiu a morte celular induzida pelo LPS. Este efeito foi compatível com os resultados da ativação do NF-кB e da expressão da iNOS. Na presença do LPS a melatonina bloqueia a indução da

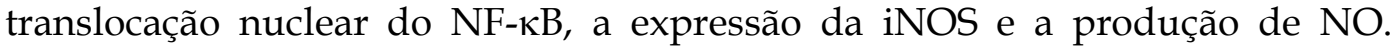
Quando apenas a melatonina foi incubada, observamos uma inibição transiente (15 min.) do NF-кB, seguida por um aumento do conteúdo nuclear do fator de transcrição (60 min.). A expressão da iNOS seguiu o mesmo perfil, ou seja, sofreu uma inibição transiente (30 min.) seguida de um aumento acima do nível basal após 120 minutos de incubação. Portanto, demonstramos que a melatonina afeta de forma diferente a viabilidade de células granulares de cerebelo dependo do contexto em que as células se encontram. Além disso, obtivemos evidências de que essas células expressam a enzima a AA-NAT, e produzem melatonina, que exerce função protetora para a cultura. Desta forma, nossos dados proporcionam uma base mecanicista para a compreensão da influência do contexto celular na resposta à melatonina. 
ABSTRACT 
Several neurons constitutively express NF- $\kappa \mathrm{B}$, which plays some physiological roles, besides the well-known control of pathological responses. Melatonin, the hormone produced by the pineal gland rhythmically in the dark phase is also an autocrine and paracrine factor of immune competent cells, involved in multiple biological processes and the cytoprotective action is a highlight of this molecule. Melatonin inhibits the nuclear translocation of NF-kB and the expression of iNOS in models of cell damage. The present study evaluated whether the cytoprotective effect of melatonin depends on the state of activation of NF- $\kappa B$ in cultured cerebellar granule cells, given that these cells have a basal activity of this transcription factor essential for cell survival. Moreover, we questioned whether these cells in culture produce melatonin and whether it would have a cytoprotective role. We tested the viability of the rat (78 days old Wistar) cerebellar granule cell culture after $24 \mathrm{~h}$ incubation with melatonin in the presence or absence of LPS. In basal condition melatonin decreased cell survival while inhibited cell death induced by LPS. These effects were consistent with the results from the activation of $N F-\kappa B$ and the expression of iNOS. In the presence of LPS melatonin blocked the activation of the NF- $\kappa B$, the expression of iNOS and the production of NO. When only melatonin was incubated, we observed a transient reduction (15 min) of NF- $\mathrm{BB}$ nuclear content, followed by an increase of its nuclear content (60 min). The iNOS expression followed the same profile, i.e. undergone a transient inhibition (30 $\mathrm{min}$ ), followed by an increase above baseline after $120 \mathrm{~min}$ of incubation. Therefore, we have demonstrated that melatonin affects differently the viability of cerebellar granule cells depending on the context. Furthermore, we founded evidences that the granule cells in culture express the key enzyme in the synthesis of melatonin, AA-NAT and produce melatonin, which carries protective function for the culture. Our data provide a mechanistic basis for understanding the influence of cell context on the final output response to melatonin. 


\section{REFERÊNCIAS}


ADAMAH-BIASSI, E.B., ZHANG, Y., JUNG, H., VISSAPRAGADA, S., MILLER, R.J. \& DUBOCOVICH, M.L. (2014). Distribution of MT1 melatonin receptor promoter-driven RFP expression in the brains of $\mathrm{BAC} \mathrm{C} 3 \mathrm{H} / \mathrm{HeN}$ transgenic mice. J Histochem Cytochem, 62: 70-84.

AL-GHOUL, W.M., HERMAN, M.D. \& DUBOCOVICH, M.L. (1998). Melatonin receptor subtype expression in human cerebellum. Neuroreport, 9: 4063-4068.

ALONSO, M., COLLADO, P.S. \& GONZÁLEZ-GALLEGO, J. (2006). Melatonin inhibits the expression of the inducible isoform of nitric oxide synthase and nuclear factor kappa B activation in rat skeletal muscle. J. Pineal Res, 41: 8-14.

ARENDT, J. \& SKENE, D.J. (2005). Melatonin as a chronobiotic. Sleep Med Rev, 9: 25-39.

ASHALL, L., HORTON, C.A., NELSON, D.E., PASZEK, P., HARPER, C.V., SILLITOE, K., RYAN, S., SPILLER, D.G., UNITT, J.F., BROOMHEAD, D.S., KELL, D.B., RAND, D.A., SÉE, V. \& WHITE, M.R. (2009). Pulsatile stimulation determines timing and specificity of NF-kappaB-dependent transcription. Science, 324: 242-246.

AXELROD, J. \& WEISSBACH, H. (1960). Enzymatic O-methylation of Nacetylserotonin to melatonin. Science, 131: 1312.

BEJARANO, I., ESPINO, J., BARRIGA, C., REITER, R.J., PARIENTE, J.A. \& RODRÍGUEZ, A.B. (2011). Pro-oxidant effect of melatonin in tumor leucocytes: relation with its cytotoxic and pro-apoptotic effects. Basic Clin Pharmacol Toxicol, 108: 14-20.

BEKYAROVA, G., APOSTOLOVA, M. \& KOTZEV, I. (2012). Melatonin protection against burn-induced hepatic injury by down-regulation of nuclear factor kappa B activation. Int J Immunopathol Pharmacol, 25: 591-596.

BENÍTEZ-KING, G., RÍOS, A., MARTÍNEZ, A. \& ANTÓN-TAY, F. (1996). In vitro inhibition of $\mathrm{Ca}^{2+} /$ calmodulin-dependent kinase II activity by melatonin. Biochim. Biophys. Acta, 1290: 191-196.

BHAKAR, A.L., TANNIS, L.L., ZEINDLER, C., RUSSO, M.P., JOBIN, C., PARK, D.S., MACPHERSON, S. \& BARKER, P.A. (2002). Constitutive nuclear factor-kappa B activity is required for central neuron survival. J Neuroscience, 22: 8466-8475.

Biofactors, 35: 183-192.

BISHOP, A. \& ANDERSON, J.E. (2005). NO signalling in the CNS: from the physiological to the pathological. Toxicology, 208: 193-205. 
BLAUSTEIN, M. P. (1975). Effects of potassium, veratridine and scorpion venom on calcium accumulation and transmitter release by nerve terminals in vitro. J. Physiol, 247: 617-655.

BRUCK, R., AEED, H., AVNI, Y., SHIRIN, H., MATAS, Z., SHAHMUROV, M., AVINOACH, I., ZOZULYA, G., WEIZMAN, N. \& HOCHMAN, A. (2004). Melatonin inhibits nuclear factor kappa B activation and oxidative stress and protects against thioacetamide induced liver damage in rats. J Hepatol, 40: 86-93.

BUBENIK, G.A. (2001). Localization, physiological significance and possible clinical implication of gastrointestinal melatonin. Biol Signals Recept, 10: 350-366.

BUBENIK, G.A. (2002). Gastrointestinal melatonin: localization, function, and clinical relevance. Dig Dis Sci, 47: 2336-2348.

BUBENIK, G.A. (2008). Thirty four years since the discovery of gastrointestinal melatonin. J Physiol Pharmacol, 59: 33-51.

CAHILL, G.M. \& BESHARSE, J.C. (1993). Circadian clock functions localized in xenopus retinal photoreceptors. Neuron, 10: 573-577.

CALABRESE, V., CORNELIUS, C., RIZZARELLI, E., OWEN, J.B., DINKOVAKOSTOVA, A.T. \& BUTTERFIELD, D.A. (2009). Nitric oxide in cell survival: a janus molecule. Antioxid Redox Signal, 11: 2717-2739.

CARRILlO-VICO, A., CALVO, J.R., ABREU, P., LARDONE, P.J., GARCIAMAURIÑO, S., REITER, R.J. \& GUERRERO, J.M. (2004). Evidence of melatonin synthesis by human lymphocytes and its physiological significance: possible role as intracrine, autocrine, and/or paracrine substance. FASEB J, 18: 537-539.

CARRILLO-VICO, A., LARDONE, P. J., NAJI, L., FERNANDEZ-SANTOS, J. M., MARTIN-LACAVE, I., GUERRERO, J.M. \& CALVO, J.R. (2005). Beneficial pleiotropic actions of melatonin in an experimental model of septic shock in mice: regulation of pro-/anti-inflammatory cytokine network, protection against oxidative damage and anti-apopitotic effects. J. Pineal Res, 39: 400-408.

CARVALHO-SOUSA, C.E., DA SILVEIRA CRUZ-MACHADO, S., TAMURA, E.K., FERNANDES, P.A., PINATO, L., MUXEL, S.M., CECON, E. \& MARKUS, R.P. (2011). Molecular basis for defining the pineal gland and pinealocytes as targets for tumor necrosis factor. Front Endocrinol, 2: 10. 
CECON, E., FERNANDES, P.A., PINATO, L., FERREIRA, Z.S. \& MARKUS, R.P. (2010).

Daily variation of constitutively activated nuclear factor kappa B (NFKB) in rat pineal gland. Chronobiol Int, 27: 52-67.

CHAE, H.D., PARK, T.J., LEE, Y.K., LEE, T.G. \& KIM, K.T. (1999). Rapid and simple measurement of serotonin Nacetyltransferase activity by liquid biphasic diffusion assay. Neurochem Int, 35: 447-441.

CHEN, W. \& BALER, R. (2000). The rat arylalkylamine N-acetyltransferase E-box: differential use in a master vs. a slave oscillator. Brain Res Mol Brain Res, 81: 43-50.

CHETSAWANG, B., PUTTHAPRASART, C., PHANSUWAN-PUJITO, P., GOVITRAPONG, P. (2006). Melatonin protects against hydrogen peroxide-induced cell death signaling in SH-SY5Y cultured cells: involvement of nuclear factor kappa B, Bax and Bcl-2. J Pineal Res, 41: 116-123.

CHIK, C.L. \& HO, A.K. (1989). Multiple receptor regulation of cyclic nucleotides in rat pinealocytes. Prog Biophys Mol Biol, 53: 197-203.

COLASANTI, M., PERSICHINI, T., MENEGAZZI, M., MARIOTTO, S., GIORDANO, E., CALDARERA, C.M., SOGOS, V., LAURO, G.M. \& SUZUKI, H. (1995). Induction of nitric oxide synthase mRNA expression. Suppression by exogenous nitric oxide. J Biol Chem, 270: 26731-26733.

COSTA, E.J., LOPES, R.H. \& LAMY-FREUND, M.T. (1995). Permeability of pure lipid bilayers to melatonin. J Pineal Res, 19: 123-126.

COURTOIS, G. \& GILMORE, T.D. (2006). Mutations in the NF-kappaB signaling pathway: implications for human disease. Oncogene, 25: 6831-6943.

CRISTOFANON, S., UGUCCIONI, F., CERELLA, C., RADOGNA, F., DICATO, M., GHIBELLI, L. \& DIEDERICH, M. (2009). Intracellular prooxidant activity of melatonin induces a survival pathway involving NF-kappaB activation. Ann N Y Acad Sci, 1171: 472-478.

CUESTA, S., KIREEV, R., GARCÍA, C., FORMAN, K., ESCAMES, G., VARA, E. \& TRESGUERRES, J.A. (2011). Beneficial effect of melatonin treatment on inflammation, apoptosis and oxidative stress on pancreas of a senescence accelerated mice model. Mech Ageing Dev, 132: 573-582. 
D'MELLO, S.R., GALLI, C., CIOTTI, T. \& CAHSSANO, P. (1993). Induction of apoptosis in cerebellar granule neurons by low potassium: inhibition of death by insulin-growth factor I and CAMP. Proc Nat1 Acad Sci USA, 90: 10989-10993.

DA SILVEIRA CRUZ-MACHADO, S., CARVALHO-SOUSA, C.E., TAMURA, E.K., PINATO, L., CECON, E., FERNANDES, P.A., AVELLAR, M.C., FERREIRA, Z.S. \& MARKUS, R.P. (2010). TLR4 and CD14 receptors expressed in rat pineal gland trigger NFKB pathway. J Pineal Res, 49: 183-192.

DA SILVEIRA CRUZ-MACHADO, S., PINATO, L., TAMURA, E.K., CARVALHOSOUSA, C.E. \& MARKUS RP. (2012). Glia-pinealocyte network: the paracrine modulation of melatonin synthesis by tumor necrosis factor (TNF). PLoS One, 7: e40142. DAI, J., RAM, P.T., YUAN, L., SPRIGGS, L.L. \& HILL, S.M. (2001). Transcriptional repression of RORalpha activity in human breast cancer cells by melatonin. Mol Cell Endocrinol, 176: 111-120.

DELATORRE, A., SCHROEDER, R.A., PUNZALAN, C. \& KUO, P.C. (1999). Endotoxin-mediated S-nitrosylation of p50 alters NF-kappa B-dependent gene transcription in ANA-1 murine macrophages. J Immunol, 162: 4101-4108.

ESPOSITO, E. \& CUZZOCREA, S. (2010). Antiinflammatory activity of melatonin in central nervous system. Curr Neuropharmacol, 8: 228-442.

FERNANDES, P.A.C.M. \& MARKUS, R.P. (2011). Melatonin and inflammation - the role of the immune-pineal axis and the sympathetic tônus. In: Melatonin in the promotion of health $2^{\text {nd }}$ ed., cap. 28: 435-450.

FERRARI, M.F., RAIZADA, M.K. \& FIOR-CHADI, D.R. (2008). Differential regulation of the renin-angiotensin system by nicotine in WKY and SHR glia. J Mol Neurosci, 35: 151-160.

FERREIRA, Z.S., FERNANDES, P.A., DUMA, D., ASSREUY, J., AVELLAR, M.C., MARKUS, R.P. (2005). Corticosterone modulates noradrenaline-induced melatonin synthesis through inhibition of nuclear factor kappa B. J Pineal Res, 38: 182-188.

FINK, T., GLAS, M., WOLF, A., KLEBER, A., REUS, E., WOLFF, M., KIEFER, D., WOLF, B., RENSING, H., VOLK, T. \& MATHES, A.M. (2014). Melatonin receptors mediate improvements of survival in amodel of polymicrobial sepsis. Crit Care Med, $\mathbf{4 2}$ : e22-31. 
GALANO, A., TAN, D.X. \& REITER, R.J. (2011). Melatonin as a natural ally against oxidative stress: a physicochemical examination. J Pineal Res, 51: 1-16.

GALANO, A., TAN, D.X. \& REITER, R.J. (2013). On the free radical scavenging activities of melatonin's metabolites, AFMK and AMK. J Pineal Res, 54: 245-257.

GALLI, C., MEUCCI, O., SCORZIELlO, A., WERGE, T.M., CALISSANO, P. \& SCHETTINI, G. (1995). Apoptosis in cerebellar granule cells is blocked by high $\mathrm{KCl}$, forskolin, and IGF-1 through distinct mechanisms of action: the involvement of intracellular calcium and RNA synthesis. J Neurosci, 15: 1172-1179.

GALLO, V., KINGSBURY, A., BALÁZS, R. \& JØRGENSEN, O.S. (1987). The role of depolarization in the survival and differentiation of cerebellar granule cells in culture. $J$ Neurosci, 7: 2203-2213.

GAUDET, S., PALKOVITS, M. \& NAMBOODIRI, M.A. (1991). Regional distribution of arylamine and arylalkylamine $\mathrm{N}$-acetyltransferase activities in the rat brain. Brain Res, 539: 355-357.

GEPDIREMEN, A., DÜZENLI, S., HACIMÜFTÜOGLU, A., BULUCU, D. \& SÜLEYMAN, H. (2000). The effects of melatonin in glutamate-induced neurotoxicity of rat cerebellar granular cell culture. Jpn J Pharmacol, 84: 467-469.

GERN, W.A \& RALPH, C.L. (1979). Melatonin synthesis by the retina. Science, 204: 183184.

GHES., C. \& THACH, T. (2000). The cerebellum. In: Principles of Neurosciences. Kandel, E.R., Schwartz, J.H., Jessell, T.M. McGraw-Hill, $4^{\text {th }}$ ed., cap. 42.

GILAD, E., WONG, H.R., ZINGARELLI, B., VIRÁG, L., O'CONNOR, M., SALZMAN, A.L. \& SZABÓ, C. (1998). Melatonin inhibits expression of the inducible isoform of nitric oxide synthase in murine macrophages: role of inhibition of NFkappaB activation. FASEB J, 12: 685-693.

GILMORE, T.D., WOLENSKI, F.S. (2012). NF-kB: where did it come from and why? Immunol Rev, 246: 14-35.

GRIVICICH, I., REGNER, A. \& ROCHA, A.B. (2007). Morte cellular por apoptose. Rev Bras Canc, 53: 335-343.

HARDELAND R. (2009). Melatonin: signaling mechanisms of a pleiotropic agent. Biofactors, 35: 183-192. 
HARDELAND, R. (2012). Neurobiology, pathophysiology, and treatment of melatonin deficiency and dysfunction. Scientific World Journal, 2012: 640389.

HASHIMOTO, M. \& HIBI, M. (2012). Development and evolution of cerebellar neural circuits. Dev Growth Differ, 54: 373-389.

HAYDEN, M.S. \& GHOSH, S. (2004). Signaling to NF-kappaB. Genes Dev, 18: 2195-224.

HAYDEN, M.S. \& GHOSH, S. (2012). NF-kB, the first quarter-century: remarkable progress and outstanding questions. Genes Dev, 26: 203-234.

HUSSON, I., MESPLÈS, B., BAC, P., VAMECQ, J., EVRARD, P. \& GRESSENS, P. (2002). Melatoninergic neuroprotection of the murine periventricular white matter against neonatal excitotoxic challenge. Ann Neurol, 51: 82-92.

IMBESI, M., UZ, T., DZITOYEVA, S., GIUSTI, P. \& MANEV, H. (2008). Melatonin signaling in mouse cerebellar granule cells with variable native MT1 and MT2 melatonin receptors. Brain Res, 1227: 19-25.

IUVONE, P.M., TOSINI, G., HAQUE, R., KLEIN, D.C. \& CHAURASIA, S.S. (2005). Circadian Clocks, Clock-Controlled Genes and Melatonin Biosynthesis in the Retina. Prog Retin Eye Res, 24: 433-456.

IVERSEN L. (2006). Julius Axelrod: 20 May 1912 - 29 December 2004. Biogr Mem Fellows R Soc, 52: 1-13.

JANG, S.W., LIU, X., PRADOLDEJ, S., TOSINI, G., CHANG, Q., IUVONE, P.M. \& YE, K. (2010). N-acetylserotonin activates TrkB receptor in a circadian rhythm. Proc Natl Acad Sci USA, 107: 3876-3881.

JIANG-SHIEH, Y.F., WU, C.H., CHIEN, H.F., WEI, I.H., CHANG, M.L., SHIEH, J.Y. \& WEN, C.Y. (2005). Reactive changes of interstitial glia and pinealocytes in the rat pineal gland challenged with cell wall components from gram-positive and -negative bacteria. J Pineal Res, 38: 17-26.

JIMENEZ-JORGE, S., GUERRERO, J.M., JIMENEZ-CALIANI, A.J., NARANJO, M.C., LARDONE, P.J., CARRILLO-VICO, A., OSUNA, C. \& MOLINERO, P. (2006). Evidence for melatonin synthesis in the rat brain during development. J Pineal Res, 42: 240-246.

KALTSCHMIDT, B., WIDERA, D. \& KALTSCHMIDT, C. (2005). Signaling via NF-кB in the nervous system. Biochemica et Biophysica Acta, 1745: 287-299. 
KAUR, C., SIVAKUMAR, V., ZHANG, Y. \& LING, E.A. (2006). Hypoxia-induced astrocytic reaction and increased vascular permeability in the rat cerebellum. Glia, 54: 826-839.

KAWAMOTO, E.M., LEPSCH, L.B., BOAVENTURA, M.F., MUNHOZ, C.D., LIMA, L.S., YSHII, L.M., AVELLAR, M.C., CURI, R., MATTSON, M.P. \& SCAVONE, C. (2008). Amyloid beta-peptide activates nuclear factor-kappaB through an N-methyl-Daspartate signaling pathway in cultured cerebellar cells. J Neurosci Res, 86: 845-860.

KLEIN, D.C. (1985). Photoneural regulation of the mammalian pineal gland. In Everet,D \& Clark, D. (eds), Photoperiodism, Melatonin and the Pineal. Ciba Foundation Symposium, 117: 38-56.

KLEIN, D.C., AUERBACH, D.A., NAMBOODIRI, M.A.A. \& WHELER, G.H.T. (1981). Indole metabolism in the mammalian pineal gland. The Pineal Gland, 199-227.

$\mathrm{KOH}$, P.O. (2008). Melatonin regulates nitric oxide synthase expression in ischemic brain injury. J Vet Med Sci, 70: 747-750.

KOULICH, E., NGUYEN, T., JOHNSON, K., GIARDINA, C. \& D'MELLO, S. (2001). NF-kappaB is involved in the survival of cerebellar granule neurons: association of IkappaBbeta [correction of Ikappabeta] phosphorylation with cell survival. J Neurochem, 76: 1188-1198.

LANOIX, D., LACASSE, A.A., REITER, R.J. \& VAILLANCOURT, C. (2012). Melatonin: the smart killer: the human trophoblast as a model. Mol Cell Endocrinol, 348: 1-11.

LAUDON, M., NIR, I. \& ZISAPEL, N. (1988). Melatonin receptors in discrete brain areas of the male rat. Impact of aging on density and on circadian rhythmicity. Neuroendoc, 48: 577-583.

LAX, P. (2008). Melatonin inhibits nicotinic currents in cultured rat cerebellar granule neurons. J Pineal Res, 44: 70-77.

LEE, S.J., LIU, T., CHATTORAJ, A., ZHANG, S.L., WANG, L., LEE, T.M., WANG, M.M. \& BORJIGIN, J. (2009). Posttranscriptional regulation of pineal melatonin synthesis in Octodon degus. J Pineal Res, 47: 75-81.

LEÓN, J., MACÍAS, M., ESCAMES, G., CAMACHO, E., KHALDY, H., MARTÍ, M., ESPINOSA, A., GALLO, M. A. \& ACUÑA-CASTROVIEJO, D. (2000). Structure related 
inhibition of calmodulin-dependent neuronal nitric-oxide synthase activity by melatonin and synthetic kynurenines. Mol. Pharmacol, 58: 967-975.

LERNER, A.B., TAKAHASHI, Y., LEE, T.H., \& MORI, W. (1958). Isolation of melatonin, the pineal gland factor that lightens melanocytes. J Am Chem Soc, 80: 2587.

LEZOUALC'H, F., SPARAPANI, M. \& BEHL, C. (1998). N-acetyl-serotonin (normelatonin) and melatonin protect neurons against oxidative challenges and suppress the activity of the transcription factor NF-kappaB. J Pineal Res, 24: 168-78.

LILIENBAUM, A. \& ISRAËL, A. (2003). From calcium to NF-kappa B signaling pathways in neurons. Mol Cell Biol, 23: 2680-2698.

LIU, C., FUKUHARA, C., WESSEL, J.H., IUVONE, P.M. \& TOSINI, G. (2004). Localization of Aa-nat mRNA in the rat retina by fluorescence in situ hybridization and laser capture microdissection. Cell Tissue Res, 315: 197-201.

LIU, LY., HOFFMAN, G.E., FEI, XW.,LI, Z., ZHANG, ZH. \& MEI, YA. (2007). Delayed rectifier outward $\mathrm{K}+$ current mediates the migrationof rat cerebellar granule cells stimulated by melatonin. Journal of Neurochemistry, 102: 333-344.

LOTUFO, C.M., LOPES, C., DUBOCOVICH, M.L., FARSKY, S.H. \& MARKUS, R.P. (2001). Melatonin and N-acetylserotonin inhibit leukocyte rolling and adhesion to rat microcirculation. Eur J Pharmacol, 430: 351-357.

LOTUFO, C.M., YAMASHITA, C.E., FARSKY, S.H. \& MARKUS, R.P. (2006). Melatonin effect on endothelial cells reduces vascular permeability increase induced by leukotriene B4. Eur J Pharmacol, 534: 258-263.

LUCHETTI, F., CANONICO, B., BETTI, M., ARCANGELETTI, M., PILOLLI, F., PIRODDI, M., CANESI, L., PAPA, S. \& GALLI, F. (2010). Melatonin signaling and cell protection function. FASEB J, 24: 3603-3624.

MALDONADO, M.D., MORA-SANTOS, M., NAJI, L. NAJI, L., CARRASCOSASALMORAL, M.P., NARANJO, M.C. \& CALVO, J.R. (2010). Evidence of melatonin synthesis and release by mast cells. Possible modulatory role on inflammation. Pharmacol Res, 62: 282-287.

MARKUS, R.P \& FERREIRA, Z.S. (2011). The Immune-Pineal Axis: the Role of Pineal and Extra-Pineal Melatonin in Modulating Inflammation. Advances in Neuroimmune Biology, 1: 95-104. 
MARKUS, R.P., CECON, E. \& PIRES-LAPA, M.A. (2013). Immune-Pineal Axis: Nuclear Factor $\mathrm{kB}(\mathrm{NF}-\mathrm{kB})$ Mediates the Shift in the Melatonin Source from Pinealocytes to Immune Competent Cells. Int J Mol Sci, 14: 10979-10997.

MARKUS, R.P., FERREIRA, Z.S., FERNANDES, P.A. \& CECON, E. (2007). The immune-pineal axis: a shuttle between endocrine and paracrine melatonin sources. Neuroimmunomodulation, 14: 126-133.

MARTINS, E., FERREIRA, A.C.F., SKORUPA, A.L., AFECHE, S.C., CIPOLLA-NETO, J. \& COSTA-ROSA, L.F.B.P. (2004). Tryptophan consumption and indoleamines production by peritoneal cavity macrophages. J. Leukoc. Biol., 75: 1116-1121.

MATTHEWS, J.R., BOTTING, C.H., PANICO, M., MORRIS, H.R. \& HAY, R.T. (1996). Inhibition of NF-kappaB DNA binding by nitric oxide. Nucleic Acids Res, 24: 2236-2242.

MATTSON, M. P., C. CULMSEE, Z. YU, \& S. CAMANDOLA. (2000). Roles of nuclear factor $\mathrm{\kappa B}$ in neuronal survival and plasticity. J. Neurochem, 74: 443- 456.

MENENDEZ-PELAEZ, A. \& REITER, R.J. (1993). Distribution of melatonin in mammalian tissues: the relative importance of nuclear versus cytosolic localization. $J$ Pineal Res, 15: 59-69.

MIN, K.J., JANG, J.H. \& KWON, T.K. (2012). Inhibitory effects of melatonin on the lipopolysaccharide-induced CC chemokine expression in BV2 murine microglial cells are mediated by suppression of Akt-induced NF-kB and STAT/GAS activity. J Pineal Res, 52: 296-304.

MOORE, R.Y. \& KLEIN, D.C. (1974). Visual pathways and the central neural control of a circadian rhythm in pineal serotonin $N$-acetyltransferase activity. Brain Res, 71: 17-33.

MOTULSKY, H.J. (2007). Prism 5 Statistics Guide, 2007, GraphPad Software Inc., San Diego CA, www.graphpad.com.

MUXEL, S.M., PIRES-LAPA, M.A., MONTEIRO, A.W., CECON, E., TAMURA, E.K., FLOETER-WINTER, L.M. \& MARKUS, R.P. (2012). NF-kB drives the synthesis of melatonin in RAW 264.7 macrophages by inducing the transcription of the arylalkylamine-N-acetyltransferase (AA-NAT) gene. PLoS One, 7: e52010.

NARANJO, M.C., GUERRERO, J.M., RUBIO, A., LARDONE, P.J., CARRILLO-VICO, A., CARRASCOSA-SALMORAL, M.P., JIMÉNEZ-JORGE, S., ARELLANO, M.V., 
LEAL-NOVAL, S.R., LEAL, M., LISSEN, E. \& MOLINERO, P. (2007). Melatonin biosynthesis in the thymus of humans and rats. Cell Mol Life Sci, 64: 781-790.

NEGI, G., KUMAR, A. \& SHARMA, S.S. (2011). Melatonin modulates neuroinflammation and oxidative stress in experimental diabetic neuropathy: effects on NF-kB and Nrf2 cascades. J Pineal Res, 50: 124-131.

NELSON, D.E., IHEKWABA, A.E., ELLIOTT, M., JOHNSON, J.R., GIBNEY, C.A., FOREMAN, B.E., NELSON, G., SEE, V., HORTON, C.A., SPILLER, D.G., EDWARDS, S.W., MCDOWELL, H.P., UNITT, J.F., SULLIVAN, E., GRIMLEY, R., BENSON, N., BROOMHEAD, D., KELL, D.B., WHITE, M.R. (2004). Oscillations in NF-kappaB signaling control the dynamics of gene expression. Science, 306: 704-708.

NEUMANN, M. \& NAUMANN, M. (2007). Beyond IkappaBs: alternative regulation of NF-kappaB activity. FASEB J, 21: 2642-2654.

NOSJEAN, O., FERRO, M., COGE, F., BEAUVERGER, P., HENLIN, J. M., LEFOULON, F., FAUCHERE, J. L., DELAGRANGE, P., CANET, E. \& BOUTIN, J. A. (2000). Identification of the melatonin-binding site MT3 as the quinone reductase 2. J. Biol. Chem. 275: 31311-31317.

ORTIZ, G.G., BENÍTEZ-KING, G.A., ROSALES-CORRAL, S.A., PACHECO-MOISÉS, F.P. \& VELÁZQUEZ-BRIZUELA, I.E. (2008). Cellular and biochemical actions of melatonin which protect against free radicals: role in neurodegenerative disorders. Curr Neuropharmacol, 6: 203-214.

OXENKRUG, G. (2005). Antioxidant effects of N-acetylserotonin: possible mechanisms and clinical implications. Ann N Y Acad Sci, 1053: 334-347.

PANDI-PERUMAL, S.R., BAHAMMAM, A.S., BROWN, G.M., SPENCE, D.W., BHARTI, V.K., KAUR, C., HARDELAND, R. \& CARDINALI, D.P. (2013). Melatonin antioxidative defense: therapeutical implications for aging and neurodegenerative processes. Neurotox Res, 23: 267-300.

PANDI-PERUMAL, S.R., SRINIVASAN, V.,MAESTRONI, G.J.M, CARDINALI, D.P., POEGGELER, B. \& HARDELAND, R. (2006). Melatonin: Nature's most versatile biological signal? FEBS Journal, 273: 2813-2838.

PANDI-PERUMAL， S.R., TRAKHT, I., SRINIVASAN, V., SPENCE, D.W., MAESTRONI, G.J., ZISAPEL, N. \& CARDINALI, D.P. (2008). Physiological effects of 
melatonin: role of melatonin receptors and signal transduction pathways. Prog Neurobiol, 85: 335-353.

PARK, O.K., YOO, K.Y., LEE, C.H., CHOI, J.H., HWANG, I.K., PARK, J.H., KWON, Y.G., KIM, Y.M. \& WON, M.H. (2010). Arylalkylamine N-acetyltransferase (AANAT) is expressed in astrocytes and melatonin treatment maintains AANAT in the gerbil hippocampus induced by transient cerebral ischemia. J Neurol Sci, 294: 7-17.

PARK, S.K., LIN, H.L. \& MURPHY, S. (1994). Nitric oxide limits transcriptional induction of nitric oxide synthase in CNS glial cells. Biochem Biophys Res Commun, 201: 762-768.

PARK, S.W., HUQ, M.D., HU, X. \& WEI, L.N. (2005). Tyrosine nitration on p65: a novel mechanism to rapidly inactivate nuclear factor-kappaB. Mol Cell Proteomics, 4: 300-309.

PAUL, S.M., HSU, L.L. \& MANDELL, A.J. (1974). Extrapineal N-acetyltransferase activity in rat brain. Life Sci, 15: 2135-2143.

PENG, H.B., LIBBY, P. \& LIAO, J.K. (1995). Induction and stabilization of I kappa B alpha by nitric oxide mediates inhibition of NF-kappa B. J Biol Chem, 270: 14214-14219. PERREAU, V.M., BONDY, S.C., COTMAN, C.W., SHARMAN, K.G. \& SHARMAN, E.H. (2007). Melatonin treatment in old mice enables a more youthful response to LPS in the brain. J Neuroimmunol, 182: 22-31.

PINATO, L., DA SILVEIRA CRUZ-MACHADO, S., FRANCO, D.G., CAMPOS, L.M., CECON, E., FERNANDES, P.A., BITTENCOURT, J.C. \& MARKUS, R.P. (2013). Selective protection of the cerebellum against intracerebroventricular LPS is mediated by local melatonin synthesis. Brain Struct Funct, in press.

PIRES-LAPA, M.A., TAMURA, E.K., SALUSTIANO, E.M. \& MARKUS, R.P. (2013). Melatonin synthesis in human colostrum mononuclear cells enhances dectin-1mediated phagocytosis by mononuclear cells. J Pineal Res, 55: 240-246.

PIZZA V., AGRESTA, A., D'ACUNTO, C.W., FESTA, M. \& CAPASSO, A. (2011). Neuroinflammation and ageing: current theories and an overview of the data. Rev Recent Clin Trials, 6: 189-203.

PONTES, G.N., CARDOSO, E.C., CARNEIRO-SAMPAIO, M.M. \& MARKUS, R.P. (2006). Injury switches melatonin production source from endocrine (pineal) to 
paracrine (phagocytes) - melatonin in human colostrum and colostrum phagocytes. $J$ Pineal Res, 41: 136-141.

PONTES, G.N., CARDOSO, E.C., CARNEIRO-SAMPAIO, M.M. \& MARKUS, R.P. (2007). Pineal melatonin and the innate immune response: the TNF-alpha increase after cesarean section suppresses nocturnal melatonin production. J Pineal Res, 43: 365-371.

PSARAKIS, S., PULIDO, O.M., BROWN, G.M., GROTA, L.J. \& SMITH, G.K. (1982). Identification and quantification of nacetylserotonin (NAS) in the developing hippocampus of the rat. Prog Neuropsychopharmacol Biol Psychiatry, 6: 439-422.

RADOGNA, F., PATERNOSTER, L., ALBERTINI, M.C., CERELLA, C., ACCORSI, A., BUCCHINI, A., SPADONI, G., DIAMANTINI, G., TARZIA, G., DE NICOLA, M., D'ALESSIO, M. \& GHIBELLI, L. (2007). Melatonin antagonizes apoptosis via receptor interaction in U937 monocytic cells. J Pineal Res, 43: 154-62.

RADOGNA, F., PATERNOSTER, L., DE NICOLA, M., CERELLA, C., AMMENDOLA, S., BEDINI, A., TARZIA, G., AQUILANO, K., CIRIOLO, M. \& GHIBELLI, L. (2009). Rapid and transient stimulation of intracellular reactive oxygen species by melatonin in normal and tumor leukocytes. Toxicol Appl Pharmacol, 239: 37-45.

RAO, P., HAYDEN, M.S., LONG, M., SCOTT, M.L., WEST, A.P., ZHANG, D., OECKINGHAUS, A., LYNCH, C., HOFFMANN, A., BALTIMORE, D. \& GHOSH, S. (2010). IkappaBbeta acts to inhibit and activate gene expression during the inflammatory response. Nature, 466: 1115-1119.

RAWASHDEH, O. \& MARONDE, E. (2012). The hormonal Zeitgeber melatonin: role as a circadian modulator in memory processing. Front Mol Neurosci, 5: 27.

RAWASHDEH, O., DE BORSETTI, N.H., ROMAN, G. \& CAHILL, G.M. (2007). Melatonin suppresses nighttime memory formation in zebrafish. Science, 318: 11441146.

REYNAERT, N.L., CKLESS, K., KORN, S.H., VOS, N., GUALA, A.S., WOUTERS, E.F., VAN DER VLIET, A. \& JANSSEN-HEININGER, Y.M. (2004). Nitric oxide represses inhibitory kappaB kinase through S-nitrosylation. Proc Natl Acad Sci USA, 101: 89458950. 
SABBAN, E.L., NANKOVA, B.B., SEROVA, L.I., KVETNANSKY, R. \& LIU, X. (2004). Molecular regulation of gene expression of catecholamine biosynthetic enzymes by stress: sympathetic ganglia versus adrenal medulla. Ann N Y Acad Sci, 1018: 370-377.

SAINZ, R.M., MAYO, J.C., RODRIGUEZ, C., TAN, D.X., LOPEZ-BURILLO, S. \& REITER, R.J. (2003). Melatonin and cell death: differential actions on apoptosis in normal and cancer cells. Cell Mol Life Sci, 60: 1407-1426.

SAINZ, R.M., REITER, R.J., TAN, D.X., ROLDAN, F., NATARAJAN, M., QUIROS, I., HEVIA, D., RODRIGUEZ, C. \& MAYO, J.C. (2008). Critical role of glutathione in melatonin enhancement of tumor necrosis factor and ionizing radiation-induced apoptosis in prostate cancer cells in vitro. J Pineal Res, 45: 258-270.

SAKAMOTO, K., LIU, C. \& TOSINI, G. (2004). Circadian Rhythms in the retina of rats with photoreceptor degeneration. J Neurochemistry, 90: 1019-1024.

SAKAMOTO, K., OISHI, K., SHIRAISHI, M., HAMANO, S., OTSUKA, H., MIYAKE, Y. \& ISHIDA, N. (2000). Two circadian oscillatory mechanisms in the mammalian retina. Neuroreport, 11: 3995-3997.

SATO, I., HIMI, T. \& MUROTA, S. (1996). Lipopolysaccharide-induced nitric oxide synthase activity in cultured cerebellar granule neurons. Neuroscience Letters, 205: 4548.

SATO, I., KIM, Y., HIMI, T. \& MUROTA, S. (1995). Induction of calcium-independent nitric oxide synthase activity in cultured cerebellar granule neurons. Neurosci Lett, 184: 145-148.

SEABRA, M.L.V., BIGNOTTO, M., PINTO, JR. L.R. \& TUFIK, S. (2000). Randomized, double-blind clinical trial, controlled with placebo, of the toxicology of chronic melatonin treatment J. Pineal Res, 29: 193-200.

SEN, R. \& BALTIMORE, D. (1986). Inducibility of $\kappa$ immunoglobulin enhancer-binding protein NF-kB by a posttranslational mechanism. Cell, 47: 921-928.

SEROVA, L.I., GUEORGUIEV, V., CHENG, S.Y. \& SABBAN, E.L. (2008). Adrenocorticotropic hormone elevates gene expression for catecholamine biosynthesis in rat superior cervical ganglia and locus coeruleus by an adrenalindependent mechanism. Neuroscience, 153: 1380-1389. 
SHIDA, C.S., CASTRUCCI, A.M. \& LAMY-FREUND, M.T. (1994). High melatonin solubility in aqueous medium. J Pineal Res, 16: 198-201.

SIMONNEAUX, V. \& RIBELAYGA, C. (2003). Generation of the melatonin endocrine message in mammals: a review of the complex regulation of melatonin synthesis by norepinephrine, peptides, and other pineal transmitters. Pharmacol Rev, 55: 325-395.

SKWARLO-SONTA, K., MAJEWSKI, P., MARKOWSKA, M., OBLAP, R. \& OLSZANSKA, B. (2003). Bidirectional communication between the pineal gland and the immune system. Can J Physiol Pharmacol, 81: 342.

SOLÍS HERRUZO, J.A. \& SOLÍS MUÑOZ, P. (2009). Melatonin and oxidative stress. Rev Esp Enferm Dig, 101: 453-459.

SOTO-MOYANO, R., BURGOS, H., FLORES, F., VALLADARES, L., SIERRALTA, W., FERNÁNDEZ, V., PÉREZ, H., HERNÁNDEZ, P. \& HERNÁNDEZ, A. (2006). Melatonin administration impairs visuo-spatial performance and inhibits neocortical long-term potentiation in rats. Pharmacol Biochem Behav, 85: 408-414.

SRINIVASAN, V., MAESTRONI, G.J., CARDINALI, D.P., ESQUIFINO, A.I., PERUMAL, S.R. \& MILLER, S.C. (2005). Melatonin, immune function and aging. Immun Ageing, 2: 17.

STEFULJ, J., HÖRTNER, M., GHOSH, M., SCHAUENSTEIN, K., RINNER, I., WÖLFLER, A., SEMMLER, J. \& LIEBMANN, P.M. (2001). Gene expression of the key enzymes of melatonin synthesis in extrapineal tissues of the rat. J Pineal Res, 30: 243247.

TAJES ORDUÑA, M., PELEGRÍ GABALDA, C., VILAPLANA HORTENSI, J., PALLÀS LLIBERIA, M. \& CAMINS ESPUNY, A. (2009). An evaluation of the neuroprotective effects of melatonin in an in vitro experimental model of age-induced neuronal apoptosis. J Pineal Res, 46: 262-267.

TAKAHASHI, Y. \& OKADA, T. (2011). Involvement of the nitric oxide cascade in melatonin-induced inhibition of long-term potentiation at hippocampal CA1 synapses. Neurosci Res, 69: 1-7.

TAMURA, E.K., CECON, E., MONTEIRO, A.W., SILVA, C.L. \& MARKUS, R.P. (2009). Melatonin inhibits LPS-induced NO production in rat endothelial cells. J Pineal Res, 46: 268-274. 
TAMURA, E.K., SILVA, C.L. \& MARKUS, R.P. (2006). Melatonin inhibits endothelial nitric oxide production in vitro. J Pineal Res, 41: 267-274.

TAN, D.X., MANCHESTER, L.C., SANCHEZ-BARCELO, E., MEDIAVILLA, M.D. \& REITER, R.J. (2010). Significance of high levels of endogenous melatonin in Mammalian cerebrospinal fluid and in the central nervous system. Curr Neuropharmacol, 8: 162-167.

TOBIN, V.A., MCCANCE, I., COLEMAN, H.A. \& PARKINGTON, H.C. (2002). How important is stimulation of alpha-adrenoceptors for melatonin production in rat pineal glands? J Pineal Res, 32: 219-224.

TOGASHI, H., SASAKI, M., FROHMAN, E., TAIRA, E., RATAN, R.R., DAWSON, T.M. \& DAWSON, V.L. (1997). Neuronal (type I) nitric oxide synthase regulates nuclear factor kappaB activity and immunologic (type II) nitric oxide synthase expression. Proc Natl Acad Sci U S A, 94: 2676-2680.

TOMÁS-ZAPICO, C. \& COTO-MONTES, A. (2005). A proposed mechanism to explain the stimulatory effect of melatonin on antioxidative enzymes. J Pineal Res, 39: 99-104.

TOSINI, G., BABA, K., HWANG, C.K. \& IUVONE, P.M. (2012a). Melatonin: an underappreciated player in retinal physiology and pathophysiology. Exp Eye Res. 103: 82-89.

TOSINI, G., YE, K. \& IUVONE, P.M. (2012b). N-acetylserotonin: neuroprotection, neurogenesis, and the sleepy brain. Neuroscientist, 18: 645-653.

TRICOIRE, H., LOCATELLI, A., CHEMINEAU, P. \& MALPAUX, B. (2002). Melatonin enters the cerebrospinal fluid through the pineal recess. Endocrinology, 143: 84-90.

TRIPATHI, D.N. \& JENA, G.B. (2010). Effect of melatonin on the expression of Nrf2 and NF-kappaB during cyclophosphamide-induced urinary bladder injury in rat. $J$ Pineal Res, 48: 324-331.

TSIEN, R.W. (1983). Calcium channel in excitable cell membrane. Ane. Re. Physiol, 42: $341-381$.

TURNER, D.A., PASZEK, P., WOODCOCK, D.J., NELSON, D.E., HORTON, C.A., WANG, Y., SPILLER, D.G., RAND, D.A., WHITE, M.R. \& HARPER, C.V. (2010). Physiological levels of TNFalpha stimulation induce stochastic dynamics of NFkappaB responses in single living cells. J Cell Sci, 123: 2834-2843. 
UZ, T., QU, T., SUGAYA, K. \& MANEV, H. (2002). Neuronal expression of arylalkylamine $\mathrm{N}$-acetyltransferase (AANAT) mRNA in the rat brain. Neurosci Res, 42: 309-316.

WANG, L.M., SUTHANA, N.A., CHAUDHURY, D., WEAVER, D.R. \& COLWELL, C.S. (2005). Melatonin inhibits hippocampal long-term potentiation. Eur J Neurosci, 22: 2231-2237.

WANG, Z., WU, L., YOU, W., JI, C. \& CHEN, G. (2013). Melatonin alleviates secondary brain damage and neurobehavioral dysfunction after experimental subarachnoid hemorrhage: possible involvement of TLR4-mediated inflammatory pathway. J Pineal Res, 55: 399-408.

WEISSBACH, H., REDFIELD, B.G. \& AXELROD, J. (1960). Biosynthesis of melatonin: enzymic conversion of serotonin to N-acetylserotonin. Biochim Biophys Acta, 43: 352353.

WIECHMANN, A.F. \& O'STEEN, W.K. (1992). Melatonin increases photoreceptor susceptibility to light-induced damage. Invest Ophthalmol Vis Sci, 33: 1894-1902.

WITT-ENDERBY, P. A., BENNETT, J., JARZYNKA, M. J., FIRESTINE, S. \& MELAN, M.A. (2003). Melatonin receptors and their regulation: biochemical and structural mechanisms. Life. Sci. 72: 2183-2198.

XIAO, W. (2004). Advances in NF-kB signaling transduction and transcription. Cellular E Molecular Immunology, 1: 425-433.

YALCIN, A., KANIT, L., \& SOZMEN, E.Y. (2004). Altered gene expressions in rat hippocampus after kainate injection with or without melatonin pre-treatment. Neurosci. Lett. 359: 65-68.

ZLOTOS, D.P., JOCKERS, R., CECON, E., RIVARA, S. \& WITT-ENDERBY, P.A. (2013). MT(1) and MT(2) Melatonin Receptors: Ligands, Models, Oligomers, and Therapeutic Potential. J Med Chem, in press. 


\section{SÚMULA CURRICULAR}

\section{Informações pessoais}

Nome completo: Daiane Gil Franco

Sexo: feminino

Data e local de nascimento: 24/08/1982; São Caetano do Sul - São Paulo, Brasil

Nacionalidade: brasileira

Endereço eletrônico:daianegfranco@yahoo.com.br

Endereço residencial: Avenida do Rio Pequeno, 120 bloco 2 apto. 73 - São Paulo - SP

CEP: 05379-000

Telefones: (11) 23860812

(11) 983167908

\section{Formação Acadêmica}

2010 - atual Doutorado no curso de Fisiologia Geral.

Instituição: Universidade de São Paulo, USP, São Paulo, Brasil.

Título: Eixo Imuno - Pineal: efeito modulador da melatonina sobre a ativação da via NF-kB em culturas de células cerebelares

Orientadora: Regina Pekelmann Markus- Universidade de São Paulo, São Paulo, Brasil.

Bolsas: Fundação de Amparo à Pesquisa do Estado de São Paulo (FAPESP/processo: 2009/17800-4).

2008 - 2010: Mestrado no curso de Fisiologia Geral.

Instituição: Universidade de São Paulo, USP, São Paulo, Brasil.

Título Dissertação: Modulação da produção de óxido nítrico por melatonina em cultura de células de cerebelo. 
Orientadora: Regina Pekelmann Markus- Universidade de São Paulo, São Paulo, Brasil.

Bolsas: Fundação de Amparo à Pesquisa do Estado de São Paulo (FAPESP/processo: 2007/06423-0).

Coordenação de Aperfeiçoamento de Pessoal de Nível Superior (CAPES 01/mar/2008 - 31/ago/2008).

2003 - 2007:Bacharel em Ciências Biológicas.

Instituição: Instituto de Biociências da Universidade de São Paulo (USP) - São Paulo, Brasil.

Titulo da iniciação científica: Melatonina modulando a atividade de colinoceptores nicotínicos em células granulares de cerebelo de rato em cultura.

Orientadora: Regina Pekelmann Markus

Bolsa de Iniciação Científica: Fundação de Amparo à Pesquisa do Estado de São Paulo (FAPESP/processo: 05/56481-0), 2005-2006; 2006-2007.

\section{Formação Complementar}

2013 - Curso de Escrita Científica, estrutura e linguagem - ministrado pelo Prof. Dr. Valtencir Zucolotto. Instituto de Biociências - Universidade de São Paulo, SP, Brasil.

2012 - Curso Transcriptomics: Assessing Genomic Networks in Normal and Diseased Brains. Society for Neurosciences, Nova Orleans, Lousiana, Estados Unidos.

2011 - Curso de curta duração em 2nd São Paulo School of Translational Sciences. Centro de tratamento, ensino e pesquisa em câncer - Hospital ACCamargo. São Paulo, SP, Brasil.

2008 - Curso de curta duração em Teoria dos Receptores. Sociedade Brasileira de Farmacologia e Terapêutica Experimental, (SBFTE). Águas de Lindóia, SP, Brasil.

2006 - Curso de curta duração em Neuroimunomodulação. Sociedade Brasileira de Farmacologia e Terapêutica Experimental, (SBFTE). Ribeirão Preto, São Paulo, Brasil. 
2005 - Curse de curta duração em Organização Neural do Sistema de Temporização Circadiana. Federação das Sociedades de Biologia Experimental (FeSBE). Águas de Lindóia, SP, Brasil.

2003 - Curso de curta duração em Teoria da Evolução. Instituto de Biociências, Universidade de São Paulo, São Paulo, Brasil.

\section{Atividades Acadêmicas com Financiamento}

2009 - Estágio de monitoria com bolsa do Programa de Aperfeiçoamento ao Ensino (PAE), junto à disciplina "Fisiologia para o Ensino Médio" dedicada aos alunos de graduação do Instituto de Biociências. Fomento: CAPES. Supervisão da Profa. Dra. Regina P. Markus.

\section{Outras Atividades Acadêmicas Relevantes}

2013 - Aula ministrada através de vídeo no Curso à Distância de Atualização para Professores "Redescobrindo a Biologia Celular: Estruturas e Funções", promovida pela profa. Dra. Patrícia Gama, pelo Instituto de Ciências Biomédicas, Universidade de São Paulo. São Paulo, SP, Brasil.

2013 - Aula ministrada no curso "Ritmos Biológicos" durante a SBPC Educação, atividade integrante da $65^{\mathrm{a}}$ Reunião Anual da Sociedade Brasileira para o Progresso da Ciências (SBPC). Recife, PE, Brasil.

2013 - Participação como pré-avaliadora da Feira Brasileira de Ciências e Engenharia (FEBRACE), 2014. São Paulo, SP, Brasil.

2013 - Participação como avaliadora da Feira Brasileira de Ciências e Engenharia (FEBRACE), na Escola Politécnica da Universidade de São Paulo, São Paulo, SP, Brasil.

2013 - Participação como avaliadora da Mostra Paulista de Ciências e Engenharia (MOP), na Secretaria de Cultura no Catavento Cultural e Educacional. São Paulo, SP, Brasil. 
2012 - Participação como avaliadora da Feira Brasileira de Ciências e Engenharia (FEBRACE), realizada na Escola Politécnica da Universidade de São Paulo. São Paulo, SP, Brasil.

2012 - Participação como avaliadora da Mostra Paulista de Ciências e Engenharia (MOP), na Secretaria de Cultura no Catavento Cultural e Educacional. São Paulo, SP, Brasil.

2011 - Participação da comissão de organização do VIII Curso de Inverno do departamento de Fisiologia do Instituto de Biociências, Universidade de São Paulo. São Paulo, SP, Brasil.

2011 - Aula ministrada no VIII Curso de Inverno - Tópicos em Fisiologia Comparada. Título: "Estudo de Casos" ministrada no módulo de "Bases Cronobiológicas da Fisiologia". Departamento de Fisiologia Geral do Instituto de Biociências Universidade de São Paulo. São Paulo, SP, Brasil.

2010 - Colaboração com o professor Rudolf Buijs do laboratório de Biologia Celular e Fisiologia do Instituto de Ciências Biomédicas da Universidade Autônoma do México, México, DF, México.

2009 - Aula ministrada no VI Curso de Inverno. - Tópicos em Fisiologia Comparada. Título: "Melatonina e Seus Diversos Aspectos" ministrada no módulo de "Fisiologia e Seus Aspectos Cronobiológicos". Departamento de Fisiologia Geral, Instituto de Biociências - Universidade de São Paulo. São Paulo, SP, Brasil.

2008 - Aula ministrada no V Curso de inverno - Tópicos em Fisiologia Comparada. Título: Melatonina e seus Diversos Aspectos. Departamento de Fisiologia Geral, Instituto de Biociências - Universidade de São Paulo. São Paulo, SP, Brasil.

2007 - Aula ministrada no IV Curso de inverno - Tópicos em Fisiologia Comparada. Título: Aspectos Evolutivos da Melatonina. Departamento de Fisiologia Geral, Instituto de Biociências - Universidade de São Paulo. São Paulo, SP, Brasil.

2004-2006 - Estágio no Laboratório de Investigação Médica (LIM-23), participando do projeto temático da FAPESP intitulado Projeto Humor, especificamente no subprojeto: Excreção noturna de 6-sulfatoximelatonina (aMT6s) como um índice preditivo do efeito de clomipramina. Instituto de Psiquiatria do Hospital das Clínicas, São Paulo/SP. Sob orientação da $\operatorname{Prof}^{\mathrm{a}} \operatorname{Dr}^{\mathrm{a}}$ Regina P. Markus e co-orientação da Prof ${ }^{\mathrm{a}}$ Dr $^{\mathrm{a}}$ Clarice Gorenstein. 


\section{Orientações e Supervisões Concluídas}

1. Márcia de Oliveira. Estágio em: Efeito protetor da melatonina em cultura de células de cerebelo: papel da glia. Sob supervisão da Profa. Dra. Regina P. Markus. No VIII Curso de inverno - Tópicos em Fisiologia Comparada. Departamento de Fisiologia Geral - Instituto de Biociências - Universidade de São Paul, 2012.

2. Paula Kempe. Estágio em: Efeito protetor da melatonina em cultura de células de cerebelo: papel da glia. Sob supervisão da Profa. Dra. Regina P. Markus. No VIII Curso de inverno - Tópicos em Fisiologia Comparada. Departamento de Fisiologia Geral - Instituto de Biociências - Universidade de São Paulo, 2012.

3. Gabriela Gomes. Estágio em: Efeito da melatonina sobre a viabilidade celular em cultura de células de cerebelo desafiadas por agentes injuriantes. Sob supervisão da Profa. Dra. Regina P. Markus. No IX Curso de inverno - Tópicos em Fisiologia Comparada. Departamento de Fisiologia Geral - Instituto de Biociências - Universidade de São Paulo, 2011.

4. Adriessa Aparecida dos Santos. Estágio em: Efeito da melatonina sobre a viabilidade celular em cultura de células de cerebelo desafiadas por agentes injuriantes. Sob supervisão da Profa. Dra. Regina P. Markus. No IX Curso de inverno - Tópicos em Fisiologia Comparada. Departamento de Fisiologia Geral - Instituto de Biociências - Universidade de São Paulo, 2011.

5. Marco Aurélio de Oliveira. Estágio em: Efeito da melatonina sobre a viabilidade celular em cultura de células de cerebelo desafiadas por agentes injuriantes. Sob supervisão da Profa. Dra. Regina P. Markus. No IX Curso de inverno - Tópicos em Fisiologia Comparada. Departamento de Fisiologia Geral - Instituto de Biociências - Universidade de São Paulo, 2011.

6. Chrystian Junqueira Alves. Estágio em: Avaliação dos efeitos da melatonina sobre os níveis de óxido Nítrico em células cerebelares de ratos tratadas com lipopolissacarídeo. Sob supervisão da Profa. Dra. Regina P. Markus. No V Curso de inverno - Tópicos em Fisiologia Comparada. Departamento de Fisiologia Geral - Instituto de Biociências - Universidade de São Paulo, 2008. 


\section{Produções Bibliográficas}

\section{Trabalhos publicados}

PINATO, L., DA SILVEIRA CRUZ-MACHADO, S., FRANCO, D.G., CAMPOS, L.M., CECON, E., FERNANDES, P.A., BITTENCOURT, J.C., MARKUS, R.P. (2013). Selective protection of the cerebellum against intracerebroventricular LPS is mediated by local melatonin synthesis. Brain Struct Funct, in press.

HIDALGO, M.P.L., CAUMO, W., DANTAS, G., FRANCO, D.G., TORRES, I.L.S., PEZZI, J., ELISABETSKY, E., DETANICO, B., PIATO, A., MARKUS, R.P. (2011). 6Sulfatoximelatonin as a predictor of clinical outcome in depressive patients treated with inhibitors of monoamine uptake. Human Psychopharmacology: Clinical and Experimental, 26: 252-257.

MARKUS, R.P., SILVA, C.L.M., FRANCO, D.G., MORTANI-BARBOSA, E., FERREIRA, Z.S. (2010). Is modulation of nicotinic acetylcholine receptors by melatonin relevant for therapy with cholinergic drugs? Pharmacology \& Therapeutics, 126: 251-262.

FRANCO, D.G. (2010). Fator de transcrição nuclear kappa b no sistema nervoso central: do fisiológico ao patológico. Revista da Biologia, 4: 35-39.

MARKUS, R., FRANCO, D., CARVALHO, L., GENTIL, V., GORENSTEIN, C. (2009). Acute increase in urinary 6-sulfatoximelatonin after clomipramine, as a predictive measure for emotional improvement. J Psychopharmacology, 24: 855-860.

\section{Trabalho submetido}

FRANCO, D.G., MARKUS, R.P. (2014). The cellular context determines the effect of melatonin on the survival of cerebellar granule cells. PLoS One.

Trabalhos publicados em anais de eventos

FRANCO, D.G., MARKUS, R.P. (2013). Melatonin modulates NF-kB/iNOS pathway in the culture of cerebellum granule cells. $3^{\text {rd }}$ FASEB Summer Research Conference on 
Melatonin Biology: Actions \& Therapeutics. Niagara Falls, Nova Iorque, Estados Unidos.

FRANCO, D.G., MARKUS, R.P. (2012). Dualistic effect of melatonin on the survival of cerebellar granule cell culture. In: Neurosciences. Nova Orleans, Luisiana, Estados Unidos.

FRANCO, D.G., SANTOS, A.A., MARKUS, R.P. (2012). Neuroprotective effects of melatonin synthesized by cerebellar granule cells cultures. In: $10^{\text {th }}$ International Congress of Cell Biology and 16 $6^{\text {th }}$ Congress of the Brazilian Society for Cell Biology. Rio de Janeiro, Rio de Janeiro, Brasil.

FRANCO, D.G., MARKUS, R.P. (2011). Neuroprotective effects of melatonin is mediated by the inhibition of the nuclear factor kappa B (NFKB) activation in cultured cells from rat cerebellum. In: 2nd São Paulo School of Translational Science - Molecular Medicine: from bench to bedside. A.C. Camargo, São Paulo, São Paulo, Brasil.

FRANCO, D.G., MARKUS, R.P. (2011). A putative dualistic effect of melatonin in cerebellar cultured cells. In: 2nd Summer FASEB Conference - Melatonin Receptors and Actions. Snowmass Village, Snowmass, CO, Estados Unidos.

FRANCO, D.G., MARKUS, R.P. (2011). Nuclear factor kappa B as a dualistic mediator of cerebellar granule cell culture damage. In: XXVI Reunião da Federação das Sociedades de Biologia Experimental (FESBE). Rio de Janeiro, RJ, Brasil.

FRANCO, D.G., MARKUS, R.P. (2010). Melatonin inhibits the effects of lipopolysaccharide mediated by toll like receptor- 4 in cerebellum cell culture. In: XV Congresso da Sociedade Brasileira de Biologia Celular. São Paulo, SP, Brasil.

FRANCO, D.G., FERREIRA, Z.S., MARKUS, R.P. (2009). A putative protective role of melatonin on granule cerebellar cells challenged with lipopolysaccharide. In: $41^{\text {o }}$ Congresso Brasileiro de Farmacologia e Terapêutica Experimental. Ribeirão Preto, SP, Brasil.

FRANCO, D.G., GOREINSTEIN, C., MARKUS, R.P. (2008). Melatonin as predictive marker for the effect of clomipramine on humor changes in normal subjects. In: FASEB Summer Conference - Melatonin Receptors: Actions and Therapeutics. Snowmass Village, Snowmass, CO, Estados Unidos. 
FRANCO, D.G., FERREIRA, Z.S., MARKUS, R.P. (2006). Excreção noturna de 6sulfatoximelatonina (aMT6s) como um índice preditivo do efeito de clomipramina. In: Simpósio de Iniciação Científica da Universidade de São Paulo. Ribeirão Preto, SP, Brasil.

FRANCO, D.G., FERREIRA, Z.S., MARKUS, R.P. (2006). Effect of clomipramine on melatonin profile of normal subjects. In: $38^{\circ}$ Congresso Brasileiro de Farmacologia e Terapêutica Experimental. Ribeirão Preto, SP, Brasil.

\section{Apresentação Oral em Congresso}

2010 - Apresentação oral do trabalho: Melatonin inhibits the effects of lipopolysaccharide mediated by toll like receptor- 4 in cerebellum cell culture. In: XV Congresso da Sociedade Brasileira de Biologia Celular. São Paulo, SP, Brasil.

\section{Prêmios}

2013 - Prêmio “Travel Award" conferida à apresentação do pôster: “FRANCO DG, MARKUS RP - Melatonin modulates NF-kB/iNOS pathway in the culture of cerebellum granule cells" apresentado na $3^{\text {rd }}$ FASEB Summer Research Conference on Melatonin Biology: Actions \& Therapeutics realizada em Niagara Falls, NY, Estados Unidos.

2010 - Menção Honrosa conferida à apresentação oral do trabalho: “FRANCO DG, MARKUS RP - Melatonin inhibits LPS-effects mediated by TLR-4 in rat cultured granule cerebelar cells". Selecionado como semifinalista na categoria Jovem Pesquisador - Neurosciências. In: XV Congresso da Sociedade Brasileira de Biologia Celular. São Paulo, SP, Brasil.

2009 - Menção Honrosa ao poster “FRANCO DG, MARKUS RP - A putative protective role of melatonin on granule cerebellar cells challenged with lipopolyssaccharide" no $41^{\circ}$ Congresso Brasileiro de Farmacologia e Terapêutica Experimental. Ribeirão Preto, SP, Brasil. 


\section{ANEXO I}

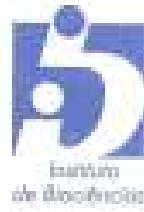

OF CFATBManzomo

Hec 2010 i 471.410

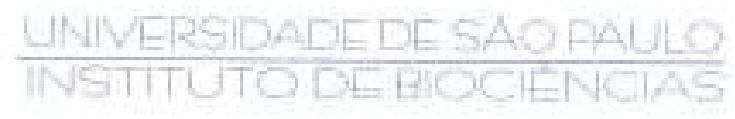

Prexadn Sentorn

Sso Paulo, 22 do thvil de 2010

Dirijo-me is V. S4. para informer que a Comisslo de Élica em Lso de Arrimnis Vertebrados em Experimeisacio do [B, em ramiso redimata bo die 2094/2010, APROVOU o Projeto Tuxo Imuno-Pmesil eforto modulador da melatumina sobre o

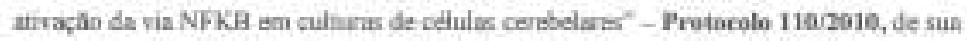

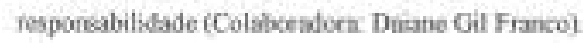

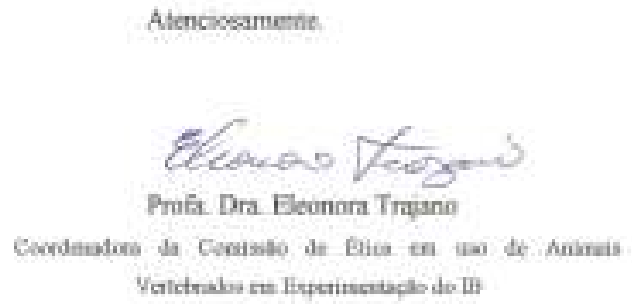

IIma Sin.

PML Dra REGNA PEKEL MANN MARKUS

Departamento de Fisiologia do fitssp

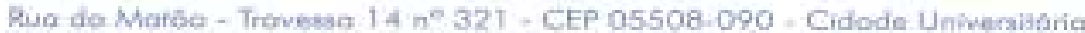

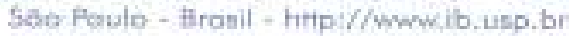

